\title{
Chorus, ECH, and Z mode emissions observed at Jupiter and Saturn and possible electron acceleration
}

\author{
J. D. Menietti, ${ }^{1}$ Y. Y. Shprits, ${ }^{2,3}$ R. B. Horne, ${ }^{4}$ E. E. Woodfield, ${ }^{4}$ G. B. Hospodarsky, ${ }^{1}$ \\ and D. A. Gurnett ${ }^{1}$ \\ Received 3 August 2012; revised 18 October 2012; accepted 18 October 2012; published 12 December 2012.
}

[1] In this paper we compare and contrast chorus, electron cyclotron harmonics (ECH), and $\mathrm{Z}$ mode emissions observed at Jupiter and Saturn and relate them to recent work on electron acceleration at Earth. Intense chorus emissions are observed near the magnetic equator, the likely source region, but the strongest intensities are on either side of the magnetic equator. Chorus intensities at Jupiter are generally about an order of magnitude larger than at Saturn, and the bandwidth of chorus at Jupiter can reach 7 or $8 \mathrm{kHz}\left(\sim 0.6 \mathrm{f}_{\mathrm{c}}\right)$, while at Saturn it is typically $<2 \mathrm{kHz}\left(\sim 0.6 \mathrm{f}_{\mathrm{c}}\right.$, also). No higher-latitude information is available at Jupiter; however, high inclination orbits at Saturn by Cassini reveal strong chorus intensities at latitudes extending to over $30^{\circ}$. At Jupiter, initial studies reveal the chorus intensities are sufficient to accelerate electrons by a stochastic process; however, the high density levels near the source region of chorus at Saturn indicate a less efficient process except for local regions such as within plasma injection regions. The role of $\mathrm{Z}$ mode in electron acceleration and the role of ECH waves in pitch angle scattering at both Jupiter and Saturn require further study.

Citation: Menietti, J. D., Y. Y. Shprits, R. B. Horne, E. E. Woodfield, G. B. Hospodarsky, and D. A. Gurnett (2012), Chorus, ECH, and Z mode emissions observed at Jupiter and Saturn and possible electron acceleration, J. Geophys. Res., 117, A12214, doi:10.1029/2012JA018187.

\section{Introduction and Background}

\subsection{Terrestrial Chorus Emissions}

[2] Storm-time chorus is especially important for the physics of the Earth's magnetosphere since it can significantly influence the distribution of energetic electrons in the outer radiation belt [e.g., Horne and Thorne, 1998; Summers et al., 2002; Meredith et al., 2003; Horne et al., 2003b]. It has been previously shown [e.g., Tsurutani and Smith, 1974; Anderson and Maeda, 1977] that the injection of terrestrial substorm electrons in the magnetotail leads to the excitation of intense low-frequency plasma waves known as whistler mode chorus in the vicinity of the geomagnetic equator outside of the plasmasphere. These waves, in turn, can accelerate the electrons in the Earth's outer radiation belt to relativistic (MeV) energies [Horne and Thorne, 1998; Meredith et al., 2003].

\footnotetext{
${ }^{1}$ Department of Physics and Astronomy, University of Iowa, Iowa City, Iowa, USA.

${ }^{2}$ Department of Earth and Space Sciences, University of California, Los Angeles, California, USA.

${ }^{3}$ Institute of Geophysics and Planetary Physics, University of California, Los Angeles, California, USA.

${ }^{4}$ British Antarctic Survey, Cambridge, UK.

Corresponding author: J. D. Menietti, Department of Physics and Astronomy, University of Iowa, Iowa City, IA 52242, USA. (john-menietti@uiowa.edu)

(C)2012. American Geophysical Union. All Rights Reserved. 0148-0227/12/2012JA018187
}

[3] At Earth, intense, diffuse whistler mode hiss at frequencies typically less than a few kilohertz is observed within the plasmasphere and may be generated by a temperature anisotropy in the electron phase space distribution. Church and Thorne [1983], Santolik et al. [2006], and Bortnik et al. [2008] have suggested that plasmaspheric hiss may originate from whistler mode chorus waves. Bortnik et al. [2008, 2009] performed quantitative modeling providing compelling evidence that chorus is the dominant source for hiss. Natural emissions of discrete, whistler mode chorus at Earth consist of electromagnetic waves in the frequency range from a few hundred hertz to several $\mathrm{kHz}$ observed in the lower-density region outside of the plasmapause region. These emissions are most often characterized as narrow banded at $\mathrm{f}<\mathrm{f}_{\mathrm{c}} / 2$ and/or $\mathrm{f}>\mathrm{f}_{\mathrm{c}} / 2$ with an emission gap near $\mathrm{f}_{\mathrm{c}} / 2$, where $\mathrm{f}_{\mathrm{c}}$ is the electron cyclotron frequency. As discussed in Gurnett and Bhattacharjee [2005], there are two types of whistler mode emissions associated with planetary radiation zones, hiss and chorus. On a spectrogram, hiss appears diffuse and featureless. In contrast, chorus is typically narrow banded, but can extend in frequency, and is quite structured. At high-resolution chorus is seen to consist of many discrete signatures of mostly rising tones. This structure is due to nonlinear processes resulting from electrons trapped in the rotating electric field or magnetic field of a gyro resonant interaction.

[4] Recent simulations of Katoh and Omura [2007a, 2007b] and Omura et al. [2008] have provided remarkable demonstrations of the nonlinear growth of chorus emission 
and electron acceleration. The electron cyclotron resonance of whistler mode waves with energetic electrons takes place close to the geomagnetic equatorial plane [Omura et al., 1991; Nunn et al., 1997; LeDocq et al., 1998; Trakhtengerts, 1999; Santolik and Gurnett, 2003; Santolik et al., 2004]. Storm-time chorus is especially important for the physics of the Earth's magnetosphere since it can significantly influence the distribution of energetic electrons in the outer radiation belt [e.g., Horne and Thorne, 1998; Summers et al., 2002; Meredith et al., 2003; Horne et al., 2003b].

[5] Electron acceleration inside planetary and astrophysical magnetic fields is a major unresolved scientific question. Inside the Earth's radiation belts, wave-particle interactions have been very effective at accelerating electrons [cf. Horne and Thorne, 1998; Summers et al., 1998; 2002; Shprits et al., 2006a, 2006b]. These authors have shown how low-frequency chorus emissions break the first adiabatic invariant and accelerate electrons up to energies of $\sim 10 \mathrm{MeV}$. Wave power peaks outside the terrestrial plasmapause where the plasma to cyclotron frequency ratio, $\mathrm{f}_{\mathrm{p}} / \mathrm{f}_{\mathrm{c}}$, decreases rapidly, to provide a natural region, in the presence of inward plasma injections, for the generation of whistler mode waves. Horne et al. [2003a, 2005a] and Albert [2005] have shown how both pitch angle diffusion, $\mathrm{D}_{\alpha \alpha}$, and momentum diffusion, $\mathrm{D}_{\mathrm{pp}}$, increase significantly for decreasing values of $\mathrm{f}_{\mathrm{p}} / \mathrm{f}_{\mathrm{c}}$. Wave acceleration at Earth is most efficient in the region from about $4 \mathrm{R}_{\mathrm{e}}<\mathrm{r}<8 \mathrm{R}_{\mathrm{e}}$. These waves accelerate the electrons and as the electrons are transported inward by radial diffusion they gain further energy.

\subsection{Terrestrial Observations}

[6] Surveys of terrestrial chorus have been reported by Meredith et al. [2001, 2002] showing that chorus electric field amplitudes are typically $5 \times 10^{-4} \mathrm{~V} / \mathrm{m}$ and peak near 1 $\mathrm{mV} / \mathrm{m}$. Near the source region (magnetic equator), Santolik et al. [2003] reported Cluster satellite observations of chorus electric field spectral densities of $\sim 10^{-7} \mathrm{~V}^{2} \mathrm{~m}^{-2} \mathrm{~Hz}^{-1}$ and magnetic field spectral densities of $10^{-4} \mathrm{nT}^{2} / \mathrm{Hz}$ during a moderately active period $(\mathrm{Kp} \approx 3.5)$. More recent chorus studies utilizing THEMIS data by $L i$ et al. [2009, 2010] show similar intensity levels of $\mathrm{E}$ and $\mathrm{B}$ for nightside chorus at Earth. Horne and Thorne [2000, 2003] and Glauert and Horne [2005] have demonstrated how electrostatic cyclotron harmonics (ECH) as well as $\mathrm{Z}$ mode electromagnetic emission are also important in scattering or accelerating electrons. Using CRRES satellite data, Meredith et al. [2009] have surveyed terrestrial ECH waves as a possible source of diffuse aurora. They find amplitudes of these waves during active periods can exceed $1 \mathrm{mV} / \mathrm{m}$. Thorne et al. [2010] have shown that at Earth chorus is the dominant cause of diffuse auroral precipitation. Menietti and Yoon [2006] have presented observations of $\mathrm{Z}$ mode emission by the Polar satellite near the plasmapause with electric field amplitudes of $\sim 0.04 \mathrm{mV} / \mathrm{m}$. In the following sections we will compare the amplitudes of these various waves to observations at Jupiter and Saturn.

[7] Using electron spectra of the highest energies, Mauk and Fox [2010] have conducted a study of the KennelPetschek limit at Earth, Jupiter, Saturn and Uranus. They conclude that whistler mode interactions at Earth, Jupiter and Uranus limit differential spectral intensities to the
Kennel-Petschek limit [Kennel and Petschek, 1966]. However, at Saturn gas and dust may be the dominant cause of limiting electron fluxes. Hospodarsky et al. [2011] have recently conducted a comparison of whistler mode chorus, hiss, magnetosonic and ECH waves at Earth, Jupiter, and Saturn. They discussed the importance of some of these waves in the acceleration of electrons. In this paper we will review some salient features of chorus, $\mathrm{ECH}$, and $\mathrm{Z}$ mode emissions observed at Earth and their role in electron acceleration and loss. Then we will examine examples of these emissions as observed by Galileo Plasma Wave Science (PWS) instrument at Jupiter and the Cassini Radio and Plasma Receiver (RPWS) at Saturn. Comparison of wave intensity, frequency extent, and source location will be made and inferences on the likelihood of relativistic electron acceleration will be made based on linear stochastic processes. The observations presented at Jupiter and Saturn are representative, but the study is not a comprehensive statistical survey. We present evidence to support the role of wave-particle interactions that enhance electron acceleration at Jupiter and Saturn.

\subsection{Past Studies of Chorus and Electron Acceleration at Jupiter}

[8] The Saturn and Jovian magnetospheres have much in common. Recently Horne et al. [2008] have conducted initial studies of pitch angle diffusion of electrons by chorus emissions at Jupiter and shown consequent stochastic acceleration of electrons to $\mathrm{MeV}$ energies. Chorus observations at Jupiter were first detected by Voyagers 1 and 2 using the 16 channel spectrum analyzer data (see review by Gurnett and Scarf [1983]). The chorus emissions were confined to a single frequency channel and were observed close to the magnetic equator. No extensive survey of chorus emission at Jupiter was possible until the Galileo mission [Menietti et al., 2008b]. The radiation belts at Jupiter are remotely observed as strong sources of synchrotron emission [cf. Berge and Gulkis, 1976; Carr et al., 1983; Bolton et al., 2002]. The emission has a peak power between $80 \mathrm{MHz}$ and $300 \mathrm{GHz}$ near $1.4 \mathrm{R}_{\mathrm{J}}\left(\mathrm{R}_{\mathrm{J}}=\right.$ radius of Jupiter $)$ where electrons with energies up to $50 \mathrm{MeV}$ can be found. These electrons are much more energetic than those usually observed in the Earth's radiation belt, and there are questions regarding the source of electron energization at Jupiter as at Earth. While radial diffusion and the interchange instability along with conservation of the adiabatic invariants as well as nonlinear effects can explain energization of electrons to over $50 \mathrm{MeV}$ in the inner zone $\left(\mathrm{r}<1.6 \mathrm{R}_{\mathrm{J}}\right)$, there are still questions about what energizes the electrons to $>1 \mathrm{MeV}$ in the middle magnetosphere or region beyond the orbit of Io [cf. Hill et al., 1983; Brice and McDonough, 1973; Thorne et al., 1997; Bolton et al., 1997].

[9] Synchrotron radiation emitted from Jupiter originates from relativistic electrons trapped inside Jupiter's magnetic field near $1.4 \mathrm{R}_{\mathrm{J}}$ with energies up to $50 \mathrm{MeV}$ [Bolton et al., 2002]. According to the widely accepted theory of radial diffusion [Brice and McDonough, 1973], electrons conserving their first adiabatic invariant are accelerated as they diffuse toward the planet by large-scale fluctuating electric fields (betatron acceleration). Inside the orbit of Io these electric fields are generated by dynamo action from winds in the ionosphere and are transmitted along the magnetic field 
into the Jovian magnetosphere. However, to attain energies of $50 \mathrm{MeV}$ at $1.4 \mathrm{R}_{\mathrm{J}}$, a source population above $1 \mathrm{MeV}$ is required in the middle magnetosphere near $10-15 \mathrm{R}_{\mathrm{J}}$. The source population has been measured in situ by satellites [Divine and Garrett, 1983], but their origin has not been resolved. Strong whistler mode chorus waves were also detected at Jupiter by the Galileo spacecraft during multiple crossings of the magnetic equator on perigee passes. This suggests that waves could provide the additional observed electron flux. The waves are excited by an unstable temperature anisotropic distribution of electrons, and grow by scattering lower energy, $\sim 10 \mathrm{keV}$ electrons into the Jovian atmosphere at small pitch angles, but also scatter electrons to higher energies at large pitch angles which remain trapped in the planetary magnetic field. In effect, the waves transfer energy from a large number of low-energy electrons to accelerate a fraction of the population to high energies. Acceleration occurs via a cyclotron resonance where the wave frequency is Doppler shifted to the cyclotron frequency of the particles. For a broad band of waves resonance can extend from energies of approximately $2 \mathrm{keV}$ up to several MeV [Horne and Thorne, 1998].

[10] It is also known that electron phase trapping is an effective means to accelerate electrons to $\mathrm{MeV}$ energies [cf. Nunn, 1974; Bell, 1984; Albert, 2002; Omura and Summers, 2006]. Summers and Omura [2007] describe an ultrarelativistic acceleration (URA) mechanism for electrons that is possible at Jupiter and other planetary magnetospheres. This mechanism involves nonlinear trapping of electrons by coherent whistler mode waves. Summers and Omura [2007] propose that under ideal conditions at Jupiter near $\mathrm{L}=8$, several hundred $\mathrm{keV}$ electrons can be energized by tens of $\mathrm{MeV}$ in a few tens of seconds (compared to weeks for a stochastic process). The electrons undergoing URA would have previously been accelerated by the process of relativistic turning acceleration [Omura et al., 2007, 2008, 2009] that has been demonstrated at Earth via simulation [cf. Katoh and Omura, 2007a, 2007b]. Using relativistic formulae, Summers et al. [2011] have recently extended the KennelPetschek limit to the nonlinear regime applicable to planetary magnetospheres.

[11] Centrifugal force from the rapid rotation of Jupiter and Saturn drives flux interchange instabilities whereby outward transport of cold dense plasma is replaced by inward transport of higher energy particles that develop temperature anisotropy and excite whistler mode waves (Jupiter: Bolton et al. [1997] and Thorne et al. [1997]; Saturn: Rymer et al. [2008] and Menietti et al., 2008a, 2008c]). This concept is discussed in some detail by Hill et al. [1983; 2005] (see also Thorne [1983, Figure 12.12], which depicts the flow of centrifugally driven plasma in the Jovian magnetosphere). Kidder et al. [2009] have recently modeled centrifugal interchange at Saturn. As discussed by Horne et al. [2008], the intensity of whistler mode waves is a maximum in a region between 6 and $10 \mathrm{R}_{\mathrm{J}}$, where flux interchange instabilities are observed. Thus the region beyond Io, and near the outer regions of the torus where the density falls off, provides a natural and plentiful source of energy to drive the waves unstable.

[12] Energy diffusion and wave acceleration is more efficient when the phase velocity of the waves is high, which occurs when the ratio of the electron plasma frequency to cyclotron frequency $\left(\mathrm{f}_{\mathrm{p}} / \mathrm{f}_{\mathrm{c}}\right)$ is low [Horne and Thorne, 1998; Horne et al., 2003b; Gurnett and Bhattacharjee, 2005], typically $<4$. Using a plasma density model for the torus [Bagenal, 1994], and a dipole magnetic field, Horne et al. [2008] found this ratio is very high inside the Io torus, but falls to a minimum in the radial range $10 \mathrm{R}_{\mathrm{J}}<\mathrm{r}<20 \mathrm{R}_{\mathrm{J}}$ due to the rapid drop in plasma density outside the Io torus. Furthermore, plasma is confined to a thin disk near the centrifugal equator as $f_{p} / f_{c}$ decreases with increasing magnetic latitude, reaching values of $\mathrm{f}_{\mathrm{p}} / \mathrm{f}_{\mathrm{c}} \sim 2.5$ at $15^{\circ}$ latitude. Thus the region beyond the orbit of Io provides the right conditions for wave acceleration and suggests that there could be an important contribution from waves at higher latitudes.

[13] As a result of the Galileo mission, in particular the Energetic Particles Detector (EPD) on board the spacecraft, a comprehensive survey of the distributions of energetic particles revealed distinct changes in the spectral slope and pitch angle distributions across magnetospheric boundaries [Tomás et al., 2004]. A transition from a trapped or pancake electron distribution (peak near $90^{\circ}$ ) to a bidirectional or butterfly distribution occurs over a narrow region $\left(<1 R_{J}\right)$ consistently in the range 9 to $17 \mathrm{R}_{\mathrm{J}}$. This range of distances at the equator magnetically maps to the Jovian diffuse or secondary auroral oval. Thorne et al. [2010] reported similar distributions related to the terrestrial diffuse aurora.

[14] Schippers et al. [2008] analyzed electron populations in Saturn's magnetosphere over the range $0.6 \mathrm{eV}$ to $10 \mathrm{MeV}$. These authors discover a population of both thermal and suprathermal electrons modeled by 2 kappa distributions with a relevant boundary near $9 R_{s}$. Hot electrons are observed to drop off inside $9 \mathrm{R}_{\mathrm{s}}$ while cold electrons drop off outside $9 R_{s}$. At and near this boundary the distribution also changes from a pancake-like or trapped population for $\mathrm{r}<9 \mathrm{R}_{\mathrm{s}}$ to a more field-aligned or butterfly distribution for $\mathrm{r}>9 \mathrm{R}_{\mathrm{s}}$ [Schippers et al., 2008, 2012]. This is very similar to observations at Jupiter as discussed above, and implies that the same processes acting at Jupiter may also explain the Kronian pitch angle distribution (PAD) boundary. This boundary is near the region where whistler mode chorus emission is observed at Saturn [Hospodarsky et al., 2008]. A survey of Katoh et al. [2011] has shown that enhanced chorus emission observed near the magnetic equator at Jupiter in the range 6 to $13 \mathrm{R}_{\mathrm{J}}$ is correlated with pancake distributions of $29-42 \mathrm{keV}$ electrons. In addition, $\mathrm{f}_{\mathrm{p}} / \mathrm{f}_{\mathrm{c}}$ is estimated to be in the range from 1 to 10 , where efficient chorus generation and electron scattering is possible.

\section{Jupiter Chorus Observations}

[15] In Figure 1 (middle) we show an example of chorus emissions observed by the Galileo spacecraft on orbit G7, near the Ganymede flyby. The plot is a frequency-versus-time spectrogram over the frequency range from $300 \mathrm{~Hz}$ to $20 \mathrm{kHz}$ with magnetic field intensity color-coded in $\mathrm{nT}^{2} \mathrm{~Hz}^{-1}$ as indicated in the color bar at the right. A number of constant-frequency interference lines are present for $5 \mathrm{kHz}<\mathrm{f}<13 \mathrm{kHz}$. Chorus emission is seen in the frequency range from a few hundred $\mathrm{Hz}$ up to, but seldom exceeding, about $\mathrm{f}_{\mathrm{c}} / 2$, where $f_{c}$ is indicated by the white line. The wave intensity is plotted as a function of spacecraft event time 


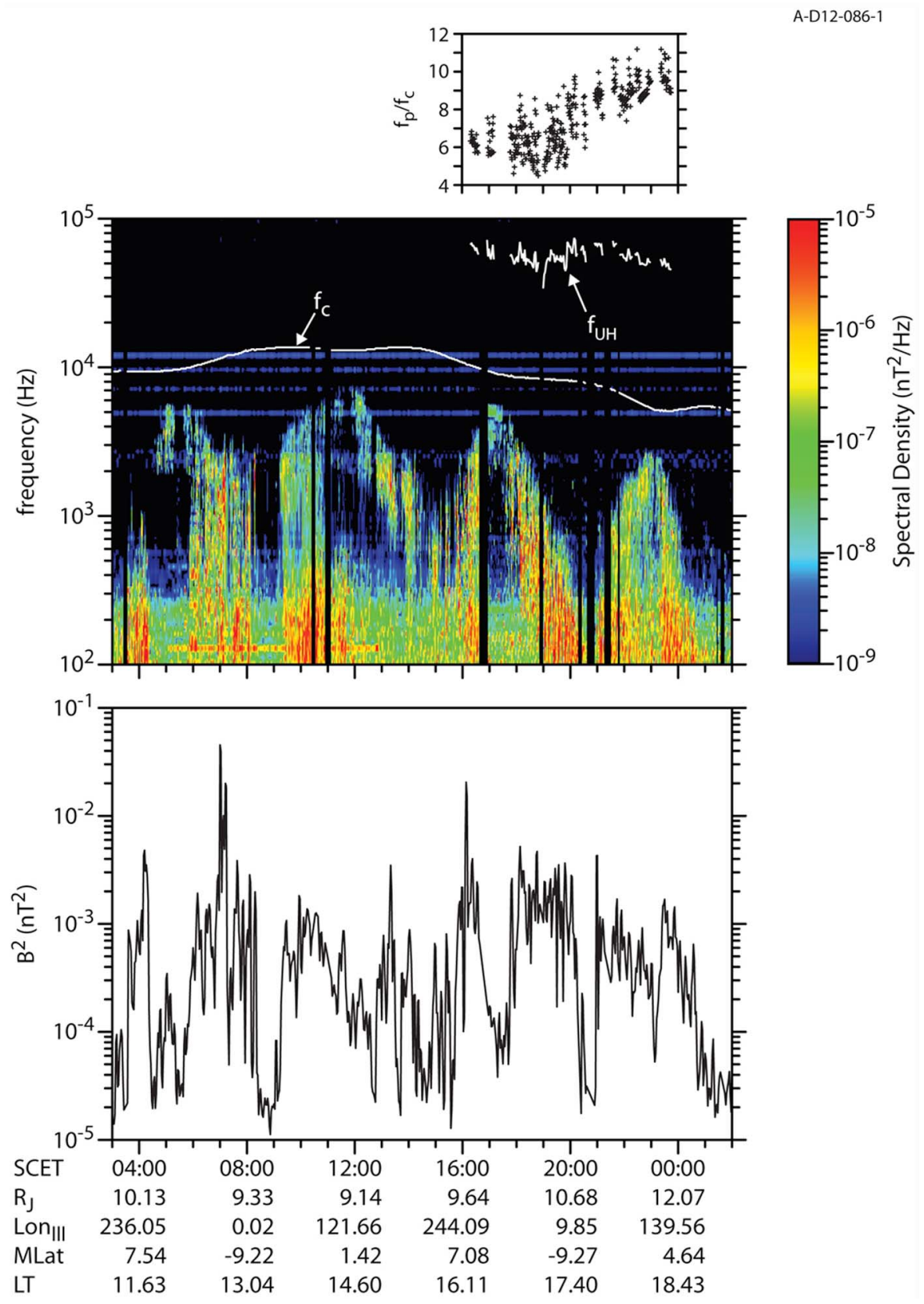

Figure 1. Day 094-095, 1997. (top) Ratio of $f_{p} / f_{c}$ evaluated for the period 16:18 to 23:44 of day 094, 1997, when the upper hybrid resonance was visible in Figure 1 (middle). The values range from a minimum $<4$ to some values ranging to $>11$. (middle) An example of chorus emissions observed by the Galileo spacecraft on orbit 7, near the Ganymede flyby (G7). The frequency range is from $100 \mathrm{~Hz}$ to $100 \mathrm{kHz}$ with magnetic field spectral density intensity color-coded in $\mathrm{nT}^{2} \mathrm{~Hz}^{-1}$ as indicated in the color bar at the right. Several constant-frequency interference lines are present for $5 \mathrm{kHz}<\mathrm{f}<13 \mathrm{kHz}$. The lower white line indicates $\mathrm{f}_{\mathrm{c}}$, while the upper white line depicts the upper hybrid resonance frequency, when it was visible in the electric field antennas. (bottom) Frequency-integrated magnetic spectral density versus time in hours for the time period of Figure 1 (middle).

(SCET), system 3 longitude (LonIII), magnetic latitude (Mlat), and local time (LT). The frequency of the chorus band peaks every time the satellite approaches the magnetic equator, forming the repeating pattern. The chorus emissions are bursty and peak power occurs at different frequencies and with different bandwidths. Note that the waves remain strong as the satellite moves to higher magnetic latitudes. The range of frequency-integrated $(100 \mathrm{~Hz}$ to $\sim 7.5 \mathrm{kHz}$ ) wave magnetic spectral density is shown in Figure 1 (bottom) to be $10^{-5}<\mathrm{B}^{2}<2 \times 10^{-2} \mathrm{nT}^{2}$, with peaks to $4 \times 10^{-2} \mathrm{nT}^{2}$. Power Flux in $\frac{\text { watts }}{m^{2}}$ can be easily obtained as $P\left(\frac{\text { watts }}{m^{2}}\right)=2.38 \times 10^{-4} B^{2}(n T)$. As noted above 

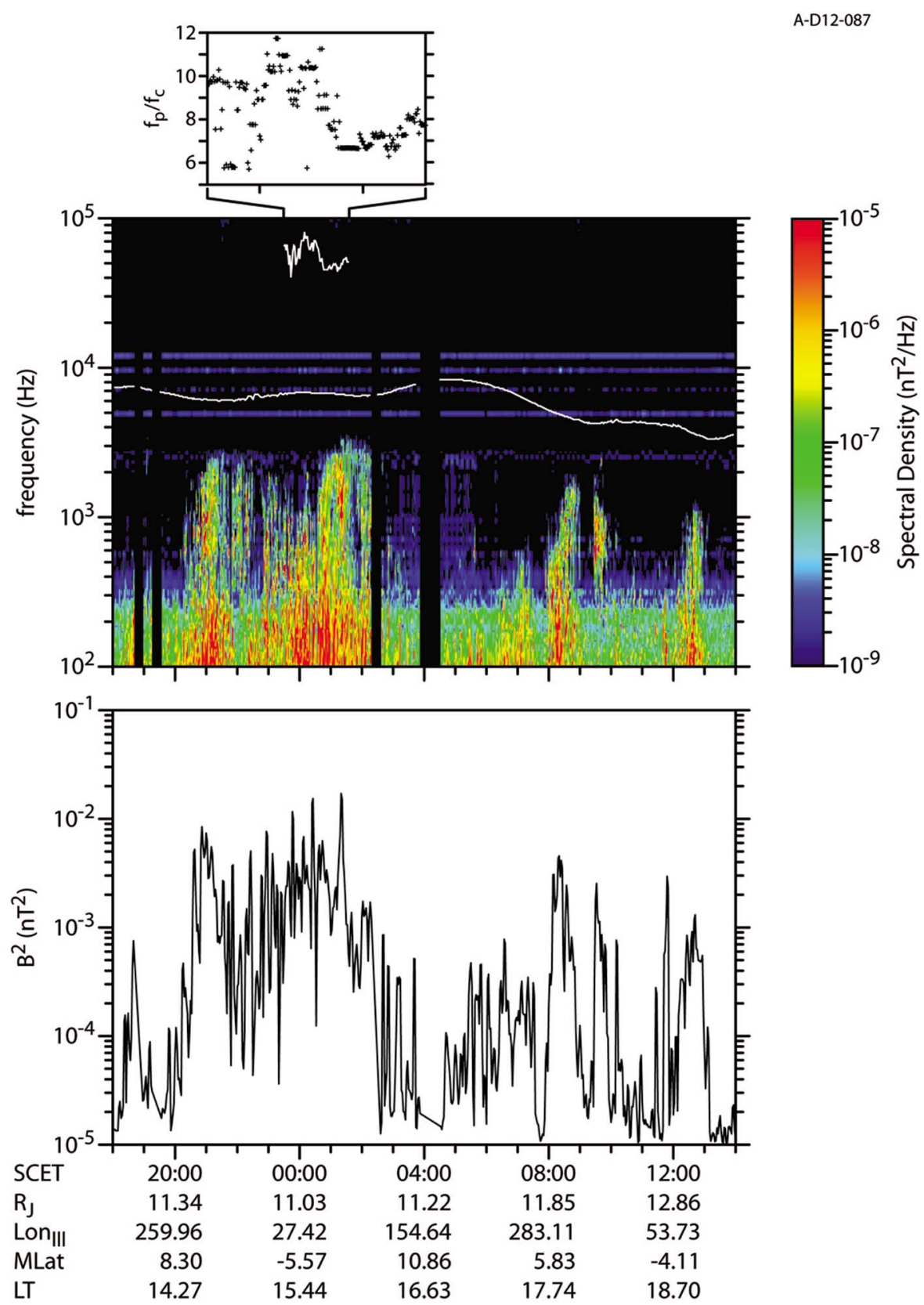

Figure 2. Day 179-180, 1996. (top) Ratio of $f_{p} / f_{c}$ for the subinterval of Figure 2 (middle) when $f_{u h}$ is known (upper white line). (middle) Frequency versus time spectrogram of the magnetic spectral density during Galileo orbit G1, in the same format as Figure 1 (top). (bottom) Frequency-integrated magnetic spectral density versus time in hours for the time period of Figure 2 (middle).

an important parameter for increasing pitch angle and momentum diffusion coefficients is $\mathrm{f}_{\mathrm{p}} / \mathrm{f}_{\mathrm{c}}$. The upper white line in Figure 1 (middle) locates observable emission near the upper hybrid resonance $\left(f_{u h}=\sqrt{f_{p}^{2}+f_{c}^{2}}\right)$, seen in the electric field data which is not shown. Upper hybrid emissions are frequently too weak to observe, therefore much of the time in Figure 1 (middle) there is no value for $\mathrm{f}_{\mathrm{uh}}$. From this value we calculate $f_{p}$ and thus $f_{p} / f_{c}$ as shown in Figure 1 (top), for orbit $\mathrm{G} 7,1997$, day $09416: 18$ to $23: 44$, with values ranging from a minimum $<4$ to some values ranging to $>11$. Horne et al. [2005a] show that for ratios $\mathrm{f}_{\mathrm{p}} / \mathrm{f}_{\mathrm{c}}>10$ energy diffusion is likely to be inefficient. The maximum density occurs within the Io plasma torus peaking near $6 \mathrm{R}_{\mathrm{J}}$ near the magnetic equator, but varying substantially with latitude.

[16] In Figures 2 and 3 we show similar results for Galileo orbits G1 and G8. Each pass shows intense chorus emissions seen periodically as the spacecraft nears the plasma sheet and magnetic equator. Chorus frequency increases near the magnetic equator, with a total bandwidth of several $\mathrm{kHz}$ for each orbit. The range of frequency-integrated wave spectral densities is $10^{-5}<\mathrm{B}^{2}<2 \times 10^{-2} \mathrm{nT}^{2}$ for $\mathrm{G} 1$, and $10^{-5}<\mathrm{B}^{2}<3 \times 10^{-3} \mathrm{nT}^{2}$ for G8. For G1 the frequency range was $100 \mathrm{~Hz}$ to $\sim 3.5 \mathrm{kHz}$ while for $\mathrm{G} 8$ the 


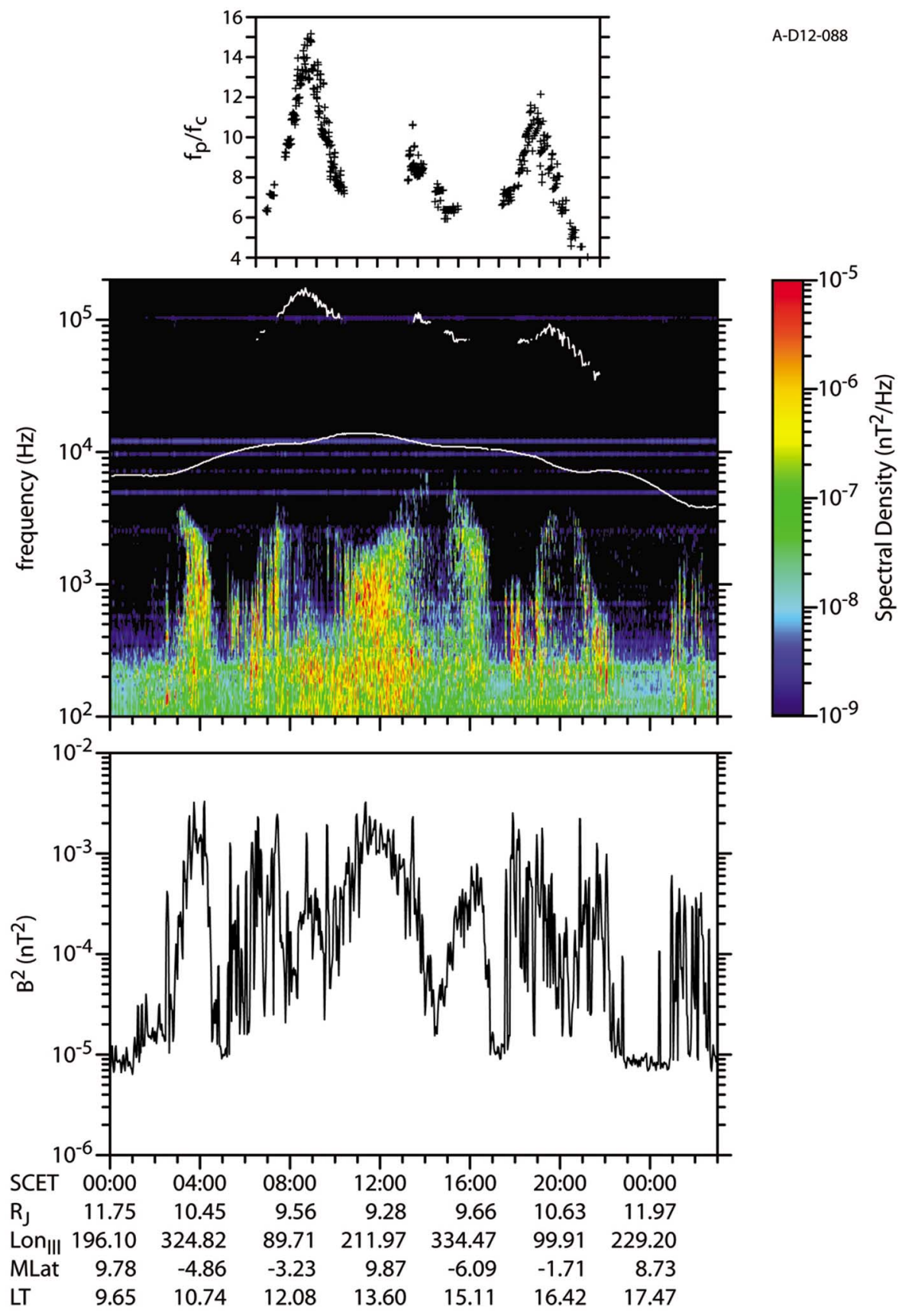

Figure 3. Day 128-129, 1997. (top) Ratio of $f_{p} / f_{c}$ for the subintervals of Figure 3 (middle) when $f_{u h}$ is known (upper white line). (middle) Frequency versus time spectrogram of the magnetic spectral density during Galileo orbit G8, in the same format as Figure 1 (middle). (bottom) Frequency-integrated magnetic spectral density versus time in hours for the time period of Figure 3 (middle).

range was $100 \mathrm{~Hz}$ to $\sim 7.5 \mathrm{kHz}$. Measured values of $\mathrm{f}_{\mathrm{p}} / \mathrm{f}_{\mathrm{c}}$ are available for subsets of the chorus emission and are seen to range from $5.5<\mathrm{f}_{\mathrm{p}} / \mathrm{f}_{\mathrm{c}}<12$ for $\mathrm{G} 1$ and $4<\mathrm{f}_{\mathrm{p}} / \mathrm{f}_{\mathrm{c}}<15$ for $\mathrm{G} 8$, showing a substantial variation with latitude and radial distance. During orbit G1 chorus is observed in the range $11<\mathrm{r}<13 \mathrm{R}_{\mathrm{J}}$, while for G8 the chorus is observed at smaller radial distances, $9.3<\mathrm{r}<13 \mathrm{R}_{\mathrm{J}}$.

[17] Wave intensity levels for each of the Jupiter passes shown in Figures 1-3 are comparable. They are quite bursty, however, and show peak values at variable frequencies. As shown in Menietti et al. [2008b] the Galileo chorus observations extend to all local times, but there is not sufficient data to obtain the extent in $\mathrm{L}$ shell at all local times.

\subsection{Jovian ECH and $\mathrm{Z}$ Mode Emission}

[18] In addition to chorus and hiss emission at Jupiter in the outer torus region, Galileo observed strong electrostatic electron cyclotron harmonic $(\mathrm{ECH})$ emission in the middle magnetosphere, often at $\mathrm{r}>10 \mathrm{R}_{\mathrm{J}}$. Kurth et al. [1980] first reported Voyager observations of such emission at Jupiter. However, due to the flyby nature of the Voyager missions, the observations of such emission were not comprehensive. 
a)

Galileo PWS ECH and Z-mode
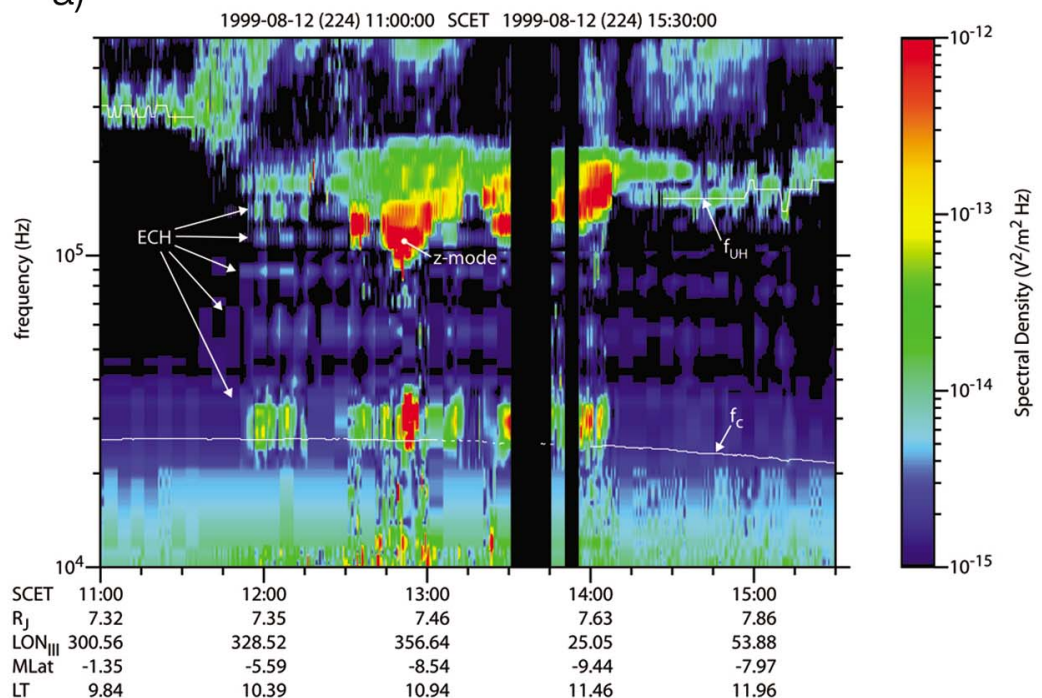

b)

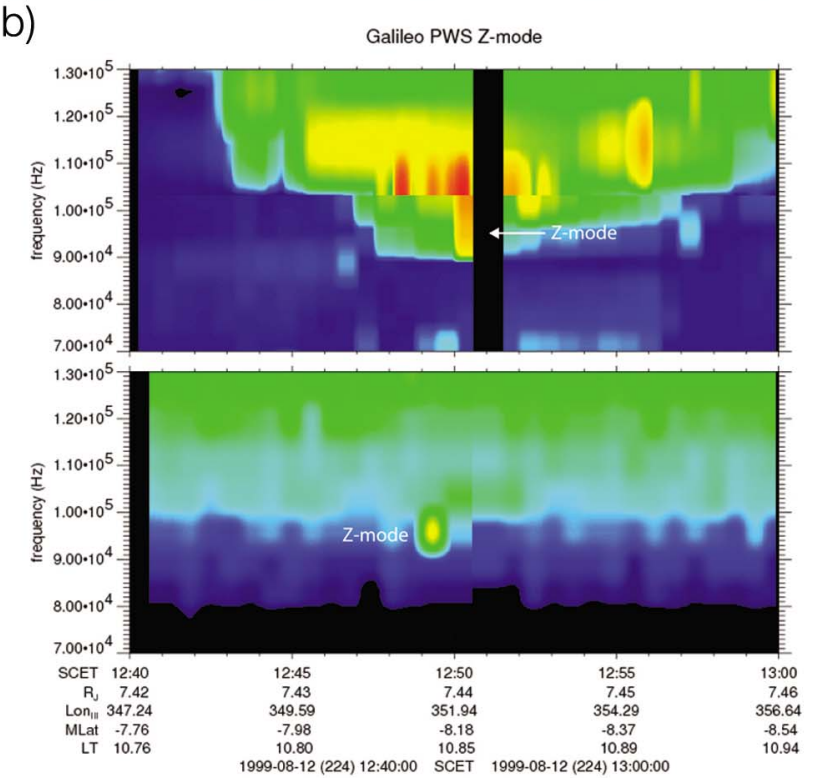

A-D12-121

A-D12-077-1

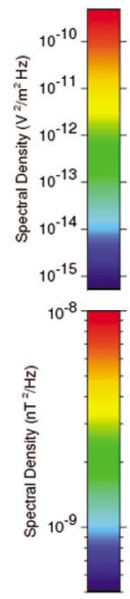

c)

Galileo PWS ECH Emission

1997-09-17 (260) 12:00:00 SCET 1997-09-20 (263) 00:00:00

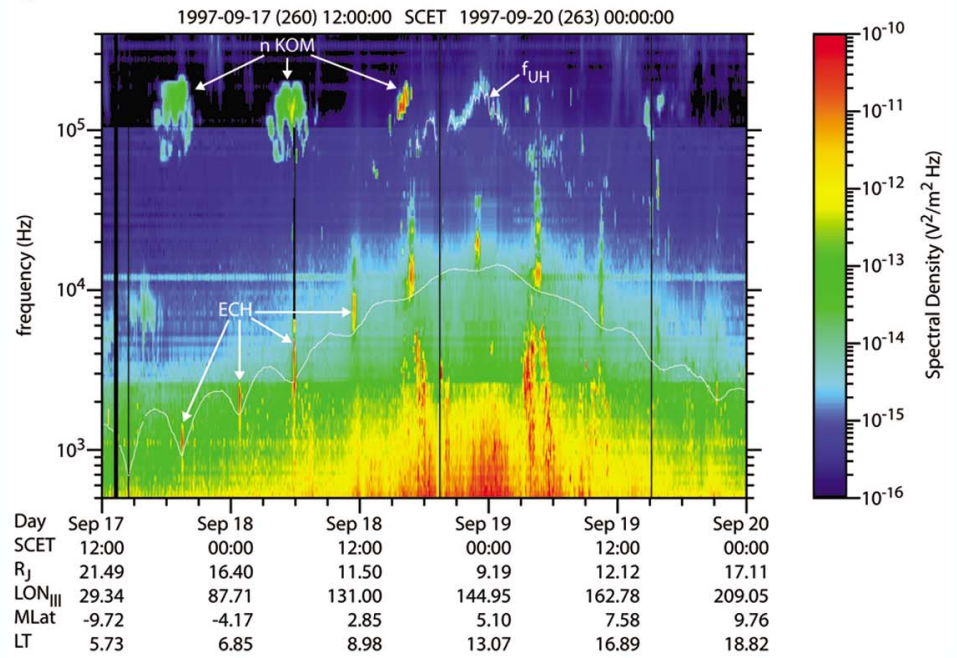

Figure 4 
Thorne [1983] discusses in some detail how such emission can contribute to the overall electron acceleration, but the lack of adequate observations of the electric field oscillations as a function of $\mathrm{L}$ made more definitive calculations difficult. Glauert and Horne [2005] have shown that Z mode emissions are likely to be quite effective at stochastic acceleration of electrons. For these waves energy diffusion can exceed pitch angle diffusion, which makes resonant interactions with electrons and possible acceleration to relativistic energies likely. As discussed by Thorne [1983] and Horne and Thorne [1998], electrostatic emission with $\mathrm{k}_{\perp} \gg \mathrm{k}_{\|}$(where $\mathrm{k}$ is the wave vector) can provide stochastic acceleration, and the production of a more pancake distribution (peak phase space distribution for pitch angles close to $90^{\circ}$ ). Such distributions can become a free energy source for chorus generation if the electron energy range includes the whistler mode resonance condition. [cf. Horne and Thorne, 2000; Horne et al., 2003a, 2003b]. More recently, however, Thorne et al. [2010] have shown that lower band chorus is the dominant source of electron precipitation, and thus the principle source for the production of pancake distributions at Earth.

[19] In Figure 4a we show a plot of electric field intensity for a $4 \mathrm{~h}$ period from 11:00 to 15:30 of day 224 of 1999, when the Galileo spacecraft was near and within the Io torus. The lower (upper) white line indicates $f_{c}\left(f_{u h}\right)$. Intense emission below $f_{c}$ is dominantly whistler mode emission. Clear examples of ECH oscillations are observed above $f_{c}$ with strong enhancements near and between the cyclotron harmonics [cf. Menietti et al., 2001]. It is probable that these strong enhancements near $f_{u h}$ include $Z$ mode emission components. We can distinguish $\mathrm{Z}$ mode because this emission is also seen on the magnetic antennas of Galileo PWS, but the intensity levels are low and the magnetic search coil maximum frequency at this time is $\sim 160 \mathrm{kHz}$. In Figure $4 \mathrm{~b}$ we show higher-resolution plots near the time labeled as $\mathrm{Z}$ mode in Figure $4 \mathrm{a}$. These plots also have a reduced and linear frequency range showing both the electric (top) and magnetic fields of the waves. The electric field spectrogram has a discontinuity near $103 \mathrm{kHz}$ due to a transition between two different wave receivers. In the magnetic spectrogram we indicate a signal enhancement centered near $96 \mathrm{kHz}$ that is associated with the electric field enhancement near 12:50. The electric receivers and the magnetic search coils at this time are operating alternately, so the two signals are not exactly simultaneous. No polarization information is available, but at this time $\mathrm{f}_{\mathrm{c}} \sim 26 \mathrm{kHz}$ and we believe $f_{p} \sim 100 \mathrm{kHz}$, perhaps associated with a density cavity. For the conditions $\mathrm{f}_{\mathrm{p}} / \mathrm{f}_{\mathrm{c}}>1$ and $\mathrm{f}_{\mathrm{c}}<\mathrm{f}<\mathrm{f}_{\mathrm{p}}$, the only free-space mode possible is $\mathrm{Z}$ mode [cf. Benson et al., $2006]$. From the measured fields we calculate $\mathrm{cB} / \mathrm{E} \sim 0.88$ for the frequency range $88.3 \mathrm{kHz}$ to $100.8 \mathrm{kHz}$. The cold plasma calculation of the index of refraction at a wave normal angle of $89.9^{\circ}$ and over the same frequency range extends from $0.2<\mathrm{n}<1.2$, and at $96 \mathrm{kHz}$, close to the strong magnetic signal, $\mathrm{n} \sim 0.64$.

[20] We have integrated the spectral density over frequency to evaluate the power level of the $\mathrm{ECH}$ waves in the region of intense emission between about 12:45 to 13:00. Peak power levels reach $\sim 10^{-9}$ watts $/ \mathrm{m}^{2}$. In Figure $4 \mathrm{c}$ we display a spectrogram of Galileo wave spectral density over the time range 12:00 of day 260 to the beginning of day 263 of 1997. This is a time interval when Galileo passed through periapsis $\left(\sim 9 R_{J}\right)$ near 00:00 of day 262 (19 September). Intense $\mathrm{ECH}$ emissions are seen for many crossings of the plasma sheet as indicated. Also indicated are chorus emission, narrowband kilometric emission (nKOM) and upper hybrid resonance emissions. We have calculated the power levels for ECH emissions as a function of frequency and time. Average peak power level for these emissions is $5.35 \times 10^{-10}$ watts $/ \mathrm{m}^{2}$.

\section{Saturn Chorus Observations}

[21] Gurnett et al. [1981] and Scarf et al. [1982] presented initial Voyager observations of chorus emissions at Saturn. These emissions were observed near the magnetic equator with narrow bandwidths and frequencies less than $\mathrm{f}_{\mathrm{c}} / 2$. They also displayed rising frequency drift structures characteristic of chorus. The Cassini mission, with its complex of radio receivers has greatly expanded our knowledge of chorus emission at Saturn [cf. Gurnett et al., 2005]. Hospodarsky et al. [2008] have reported initial observations and a survey mapping of the locations of the emissions within the Kronian magnetosphere.

[22] Whistler mode chorus has been detected by the Radio and Plasma Wave Science (RPWS) Instrument during the majority of Cassini's first fifty orbits of Saturn. At Saturn, chorus is detected in two different regions. The most common observations are of chorus propagating away from Saturn's magnetic equator, suggesting a source near the magnetic equator [cf. Hospodarsky et al., 2008, Figure 7]. This chorus is usually detected for many hours, is only observed below half the electron cyclotron frequency, occurs primarily from L shells of about 5 to 8 , and shows no obvious correlation with Saturn latitude or local time. The second region of chorus detected at Saturn is in association with local plasma injections, which will be discussed in section 3.2.

[23] In this section we present wave observations, but no electron distribution functions. It is interesting, however, to note the electron distributions associated with chorus emissions. Menietti et al. [2008c] studied chorus growth rate based on in situ electron distributions obtained by the Cassini electron spectrometer (ELS) near the magnetic equator during an equatorial orbit where moderately strong chorus

\footnotetext{
Figure 4. (a) Electric field intensity for a $4 \mathrm{~h}$ period from 11:00 to 15:30 of day 224 of 1999, when the Galileo spacecraft was near and within the Io torus. The bottom (top) white line indicates $f_{c}\left(f_{u h}\right)$. ECH and possible $Z$ mode emissions are indicated. (b) A higher time-resolution plot of Figure 4a near the region of suspected $\mathrm{Z}$ mode emission. Electric (top) and magnetic field spectral density are shown for a reduced and linear frequency range from Figure 4a. The waves display a weak but obvious magnetic component which is identified as Z mode. (c) Spectrogram of Galileo wave spectral density for a multiday period. Intense ECH emission is seen for most of the plasma sheet crossings as the spacecraft passes through periapsis near 00:00, 19 September.
} 

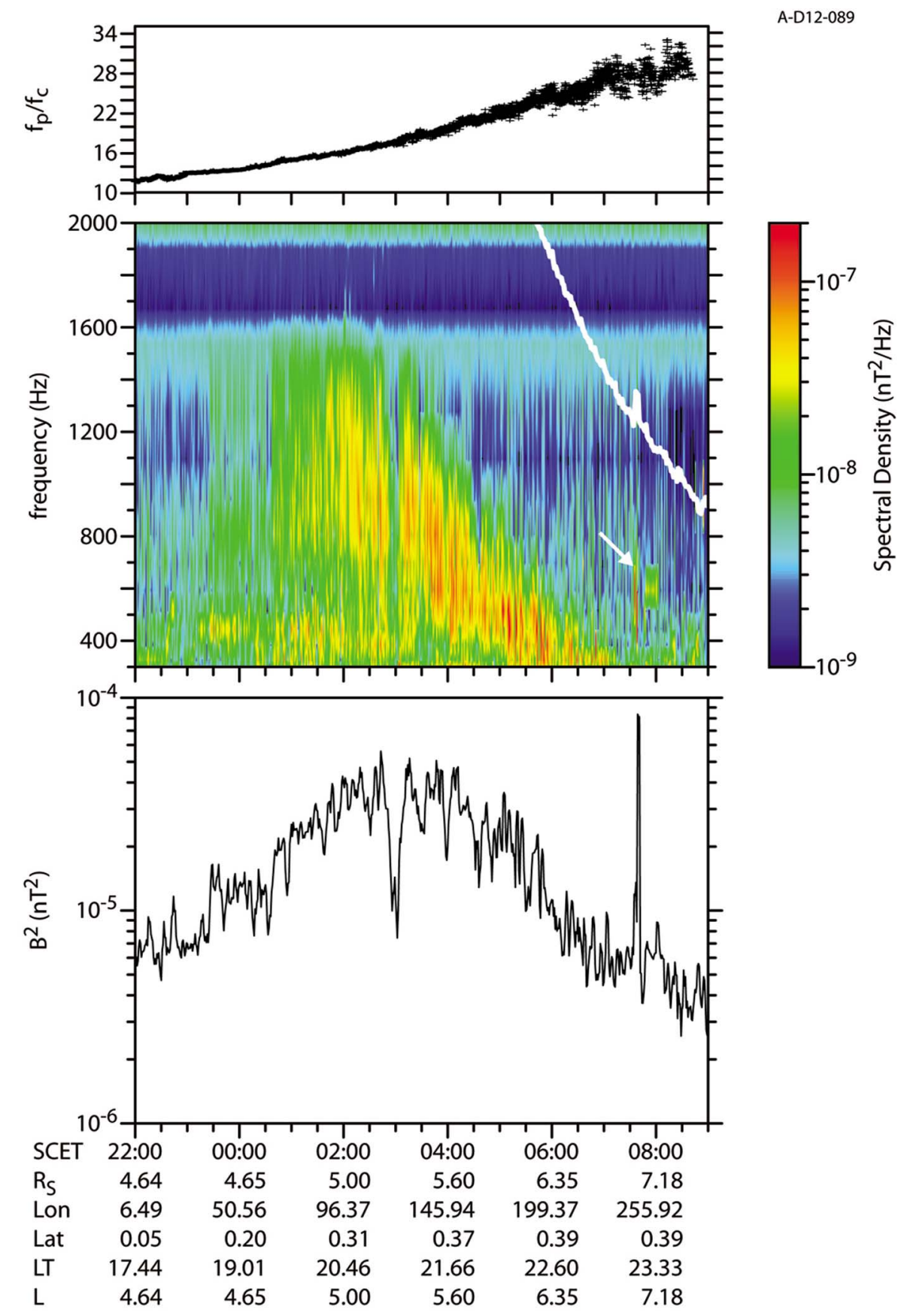

Figure 5. (top) Ratio, $\mathrm{f}_{\mathrm{p}} / \mathrm{f}_{\mathrm{c}}$ for a subinterval of Figure 5 (middle). (middle) A Cassini frequency-time spectrogram (linear frequency scale) of magnetic spectral density for days 302-303 of 2005 from the Cassini RPWS. Low-band chorus emission near the magnetic equator is observed at local times in the range $\sim 19 \mathrm{~h}<\mathrm{LT}<24 \mathrm{~h}$. (bottom) The frequency-integrated power for the chorus emissions observed for the time range of Figure 5 (middle).

emission was observed at about $L=5.3$. For that study $\mathrm{f}_{\mathrm{p}} / \mathrm{f}_{\mathrm{c}}$ $\sim 17.7$ and the whistler mode resonance energy was $\sim 1.6 \mathrm{keV}$ at $800 \mathrm{~Hz}$. A pancake distribution was observed with $\mathrm{T}_{\perp} / \mathrm{T}_{\|} \sim 2$. The observed electron distribution was modeled using a sum of Maxwellians. A warm plasma component with thermal energy $\mathrm{E}_{\text {th }} \sim 3.5 \mathrm{keV}$ and $\mathrm{T}_{\perp} / \mathrm{T}_{\|} \gtrsim$ 2 was the free energy source for the chorus. For lower values of $f_{p} / f_{c}$ (at higher latitudes) the whistler resonance energy increases, and we would expect interaction of the waves with higher-energy electrons which are available in the distribution. The electron distributions observed by Menietti et al. [2008c] with electron populations in the range of $100 \mathrm{eV}$ to $10^{4} \mathrm{eV}$ are typical of this region of the Saturn magnetosphere [cf. Schippers et al., 2008]. Most probably the chorus observed at higher latitudes (where $\mathrm{f}_{\mathrm{p}} / \mathrm{f}_{\mathrm{c}}$ $<4$ ) is generated at lower latitudes where the whistler mode resonance energy is lower, within the range of the local electron distribution. 

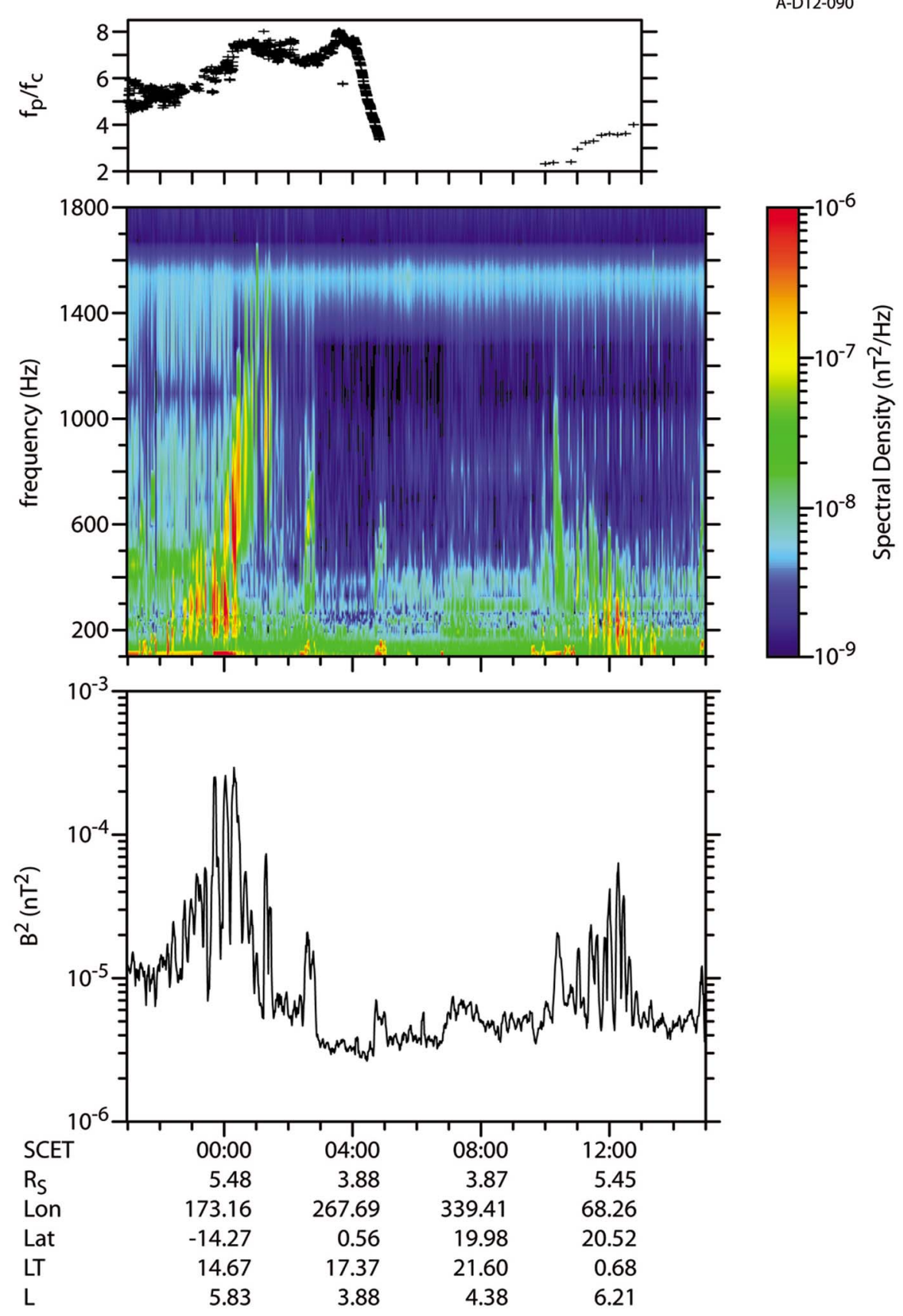

Figure 6. (top) Ratio, $\mathrm{f}_{\mathrm{p}} / \mathrm{f}_{\mathrm{c}}$ for a subinterval of Figure 6 (middle). (middle) Chorus emission for day 140, 21:00 to day 141, 15:00 of 2005. The spacecraft orbit is at higher inclination and spans a range of magnetic latitudes. The similarity between this emission and that seen at Jupiter (Figure 1) is apparent. (bottom) The frequency-integrated power for the chorus emissions observed in Figure 6 (middle).

[24] Figure 5 (middle) is a frequency-time spectrogram of magnetic spectral density of chorus emission near the magnetic equator for days 302-303 of 2005, at local times in the range $\sim 19 \mathrm{hrs}<\mathrm{LT}<24 \mathrm{~h}$, where it is often observed. Moderately intense low-band chorus $\left(f<f_{c} / 2\right)$ is seen at frequencies less than $2 \mathrm{kHz}$ and thus considerably less than observed at Jupiter. The Cassini spectrograms therefore have a linear frequency scale instead of a log scale as used for the Jupiter spectrograms. The chorus emission at Saturn is also bursty as at Jupiter and shows intensity peaks over a range of frequencies with the frequency of peak intensity and band width of the emission decreasing with latitude. Note there is a band of interference in the frequency range $\sim 1400 \mathrm{~Hz}<$ $\mathrm{f}<1600 \mathrm{~Hz}$, and another band of $\sim 300 \mathrm{~Hz}<\mathrm{f}<500 \mathrm{~Hz}$ for $t<03: 30$. Compared to typical chorus emission at Jupiter, the spectral densities are about 1 or 2 orders of magnitude lower. In Figure 5 (bottom) we display the frequency-integrated wave spectral density $(400 \mathrm{~Hz}$ to 


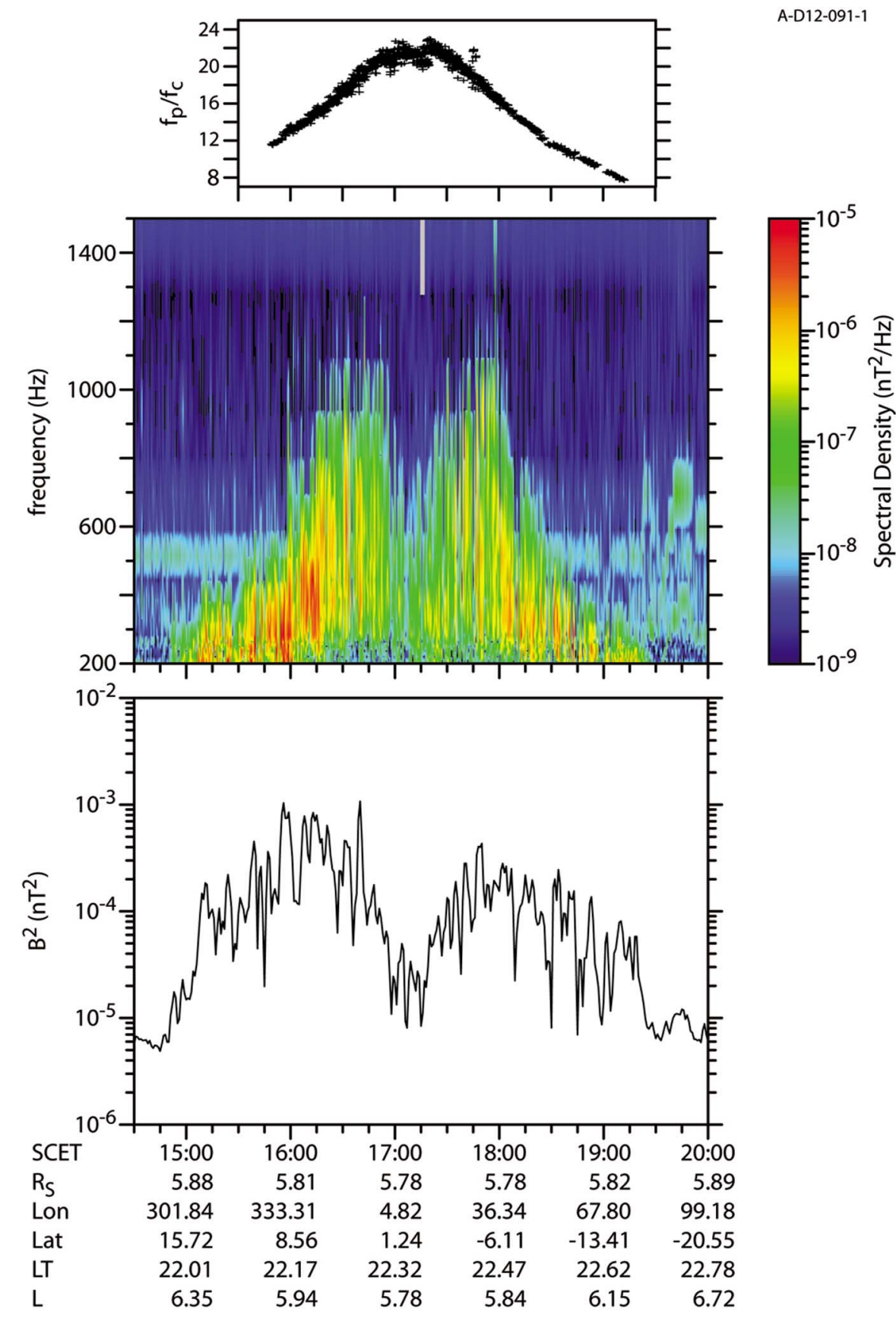

Figure 7. (top) Ratio, $\mathrm{f}_{\mathrm{p}} / \mathrm{f}_{\mathrm{c}}$ for a subinterval of Figure 7 (middle). (middle) Chorus emission for another high-inclination pass on day 352 of 2008 . The orbit is at an approximately constant $\mathrm{L}$ shell for latitudes within $10^{\circ}$ of the magnetic equator. (bottom) The frequency-integrated power $(200 \mathrm{~Hz}<\mathrm{f}<1500 \mathrm{~Hz})$ for the chorus emissions observed in Figure 7 (middle).

$1500 \mathrm{~Hz}$ ) for the chorus emissions observed in Figure 5 (middle), which are also 1 to 2 orders of magnitude lower than those typical for Jupiter. Because the emission is in a region of higher density at low latitude, during the time of chorus emission, $15<\mathrm{f}_{\mathrm{p}} / \mathrm{f}_{\mathrm{c}}<29$, which is too large to expect significant stochastic heating (Figure 5, top). The large spike near 07:35 is the result of $\mathrm{ECH}$ emission within a plasma injection indicated by the white arrow in Figure 5 (middle). This is a clear example of how such regions often show enhanced intensity levels both of $\mathrm{ECH}$ and chorus emission.

[25] Figure 6 (middle) displays chorus during an orbit at higher inclination during a $20 \mathrm{~h}$ period on days 140-141 of 2005. Because of the traversal of the magnetic equator, the similarity between this emission and that seen at Jupiter (Figure 1) is apparent. Chorus is observed in the radial range from about $4.5 \mathrm{R}_{\mathrm{s}}<\mathrm{r}<7 \mathrm{R}_{\mathrm{s}}$. The bandwidth is again less than $2 \mathrm{kHz}$, and the spectral density, peaking at $10^{-6} \mathrm{nT}^{2} \mathrm{~Hz}^{-1}$, is 
a)

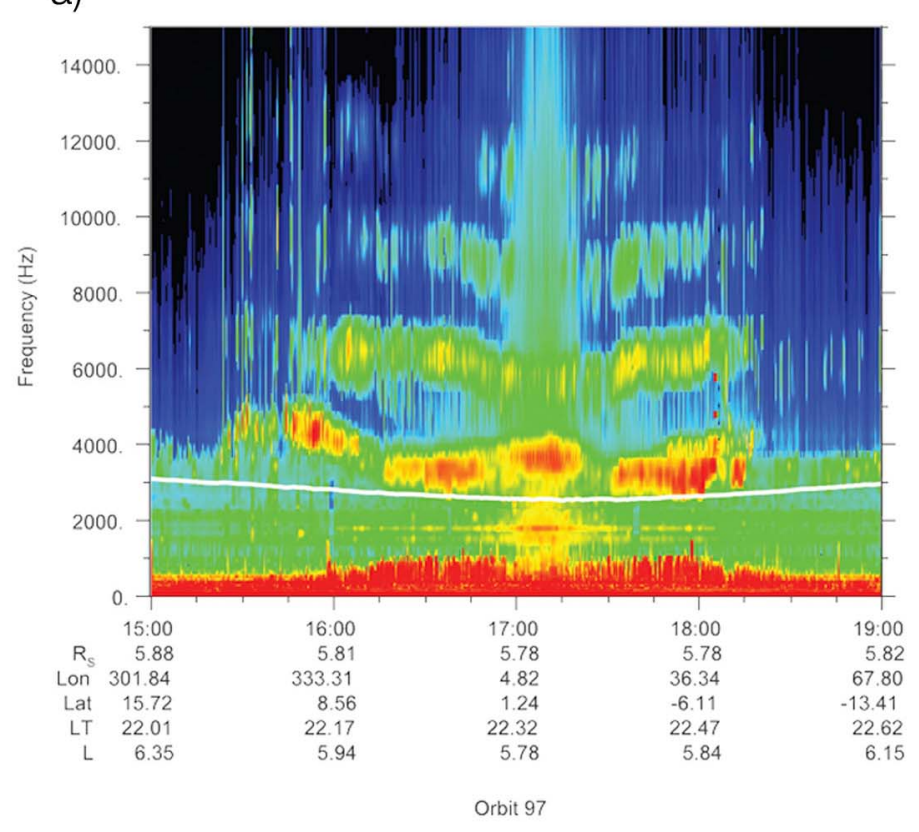

b)

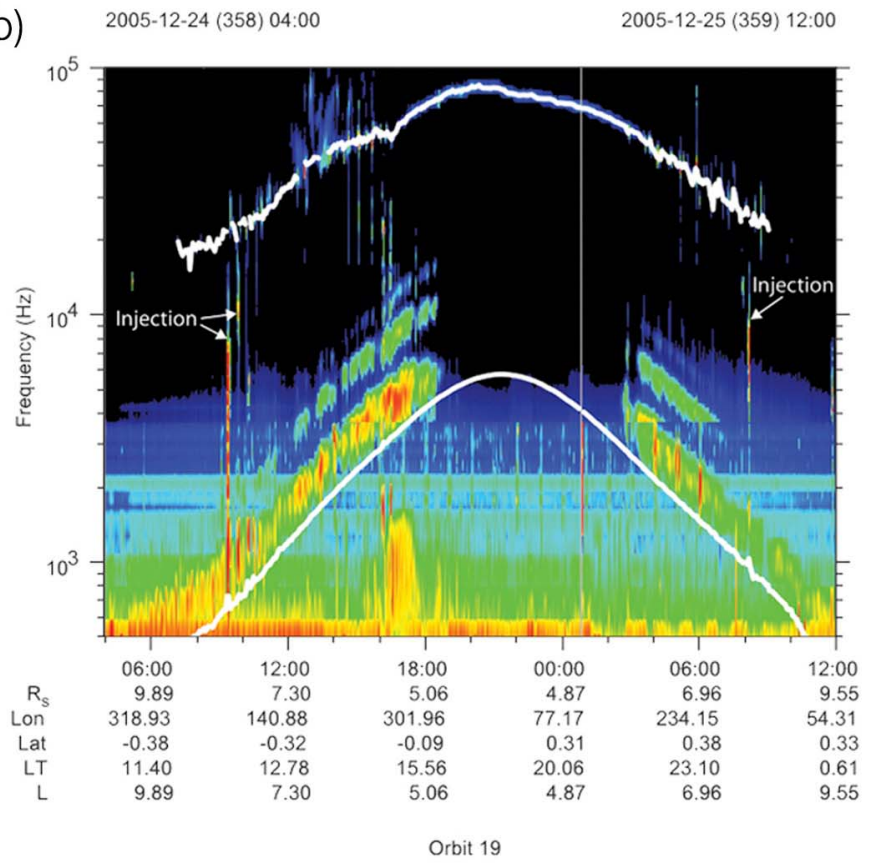

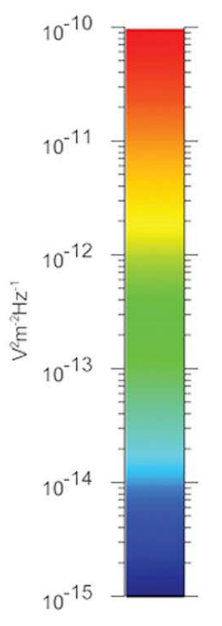

A-D12.079

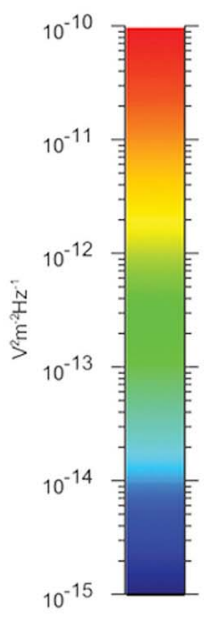

Figure 8. (a) Electrostatic cyclotron harmonic emission observed at Saturn near the equator. The data, from day 352 of 2008 show multiple harmonics as a function of latitude along a nearly constant $\mathrm{L}$ shell. (b) ECH emission observed during a portion of days 358-360 of 2005. During this period Cassini was near the magnetic equator for a range of radial distances and local times. Also indicated are a number of plasma injections, some with enhanced chorus and ECH emissions.

about an order of magnitude larger for this example than in Figure 5 (middle). Chorus is seen at both southern and northern latitudes extending to greater than $15^{\circ}$. As discussed in Thorne et al. [2005], Horne et al. [2005b], Shprits et al. [2006a, 2006b] and elsewhere, the study of chorus emission intensities and wave normal angles at higher latitudes is important. Here the waves of typically smaller wave normal angles resonate with higher-energy relativistic electrons. These waves can scatter electrons into the loss cone.

[26] This extension of chorus power to larger latitudes could not be confirmed at Jupiter because of the Galileo orbital limitations. In Figure 6 (bottom) we display the frequency-integrated spectral density for the chorus emissions observed in Figure 6 (middle). The range of frequencies is $200 \mathrm{~Hz}$ to $1500 \mathrm{~Hz}$. The chorus power levels are higher than 


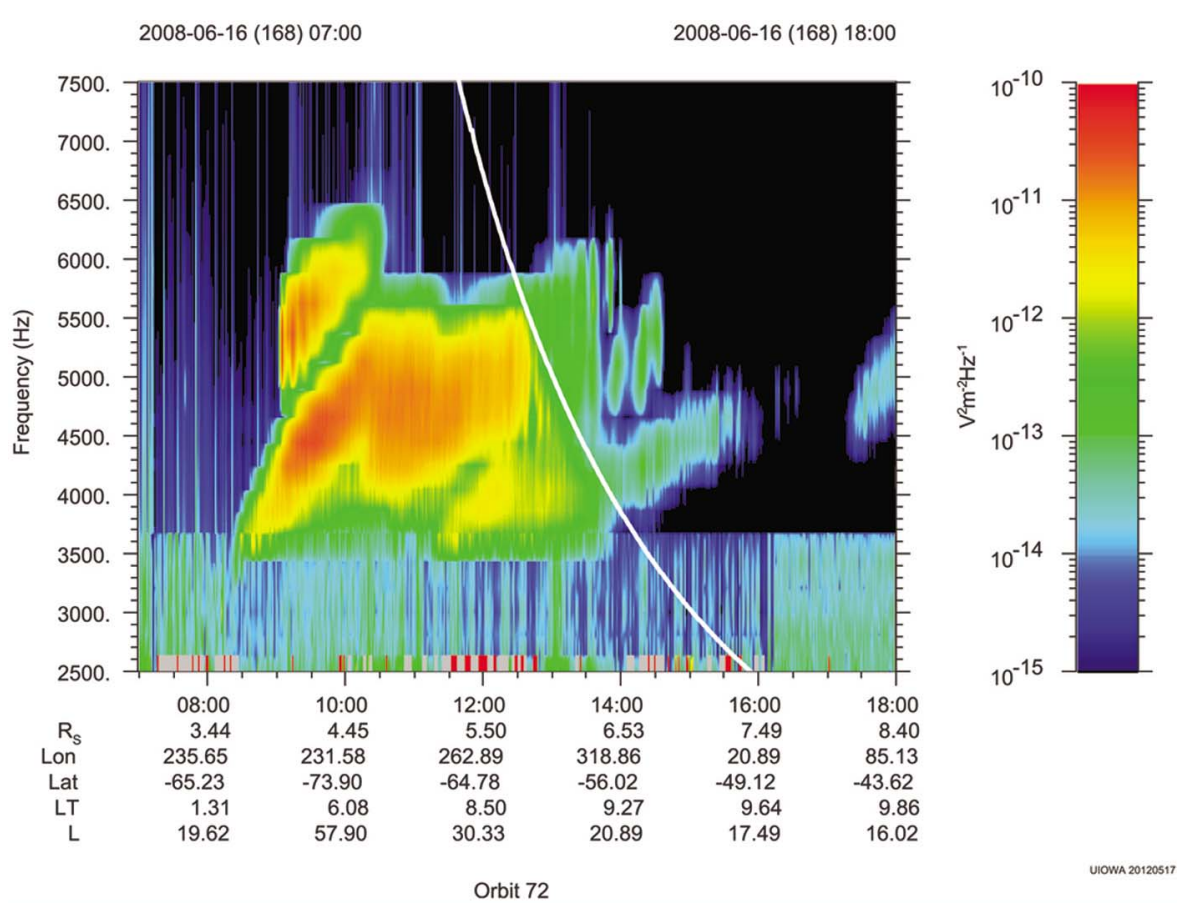

Figure 9. Emission near $5 \mathrm{kHz}$ is seen both above and below $\mathrm{f}_{\mathrm{c}}$. Below $\mathrm{f}_{\mathrm{c}}$ the emission is composed of both $\mathrm{Z}$ and $\mathrm{O}$ mode emission as discussed by Ye et al. [2010]. Above $\mathrm{f}_{\mathrm{c}}$ only weak ordinary mode emission can propagate.

those shown in Figure 5 (bottom), but about an order of magnitude lower than typically seen at Jupiter. Since the plasma frequency falls off with latitude, during the chorus emission of the southern hemisphere, $6<\mathrm{f}_{\mathrm{p}} / \mathrm{f}_{\mathrm{c}}<7.5$; while during the northern hemisphere chorus emission $2.3<\mathrm{f}_{\mathrm{p}} / \mathrm{f}_{\mathrm{c}}<$ 3.6 as shown in Figure 6 (top).

[27] Figure 7 (middle) displays chorus emission magnetic spectral density for another high-inclination pass that intercepts the magnetic equator at nearly a constant $\mathrm{L}$ shell for about $\pm 10^{\circ}$ of the magnetic equator. The chorus emission displays peak intensity at $\sim 5^{\circ}$ away from the equator, with a minimum near the equator. The bandwidth is $<1.2 \mathrm{kHz}$ and the peak spectral density is near $10^{-5} \mathrm{nT}^{-2} \mathrm{~Hz}^{-1}$.

[28] In Figure 7 (bottom) we display the frequency-integrated spectral density (over the frequency range $200 \mathrm{~Hz}<\mathrm{f}$ $<1500 \mathrm{~Hz}$ ) for the chorus emissions observed in Figure 7 (middle). These levels are higher than in the previous two examples, clearly peaking a few degrees outside the magnetic equator, but still somewhat smaller than typical Jovian chorus. During the period of broadband chorus between 16:00 to $18: 00$ the density is relatively high and we find $13<$ $\mathrm{f}_{\mathrm{p}} / \mathrm{f}_{\mathrm{c}}<21$ as seen in Figure 7 (top). While at 15:30 and 18:30 $f_{p} / f_{c}$ is 9.4 and 11.5 , respectively, still too high for efficient diffusive acceleration of electrons.

\subsection{ECH Emissions and $Z$ Mode}

[29] Intense ECH and upper hybrid emission are frequently observed in the magnetosphere of Saturn [cf. Gurnett et al., 2005; Menietti et al., 2008a]. In Figure 8a we show a plot of ECH emission observed at Saturn near the equator, where they are commonly observed. This plot of day 352 of 2008 shows multiple harmonics as a function of latitude along a nearly constant L shell. Intensity levels are in the range $10^{-13}<\mathrm{I}<10^{-10} \mathrm{~V}^{2} \mathrm{~m}^{-2} \mathrm{~Hz}^{-1}$. In contrast, Figure $8 \mathrm{~b}$ is a plot of days $358-360$ of 2005 showing ECH emission near the equator as a function of radial distance and local time. The ECH harmonics are seen near the equator, especially at smaller radial distances $\left(<7 R_{s}\right)$ when the plasma densities (indicated by the upper hybrid frequency, $f_{u h}$ ) and electron phase space density are sufficient to support generation. The electric field spectral densities range to $10^{-10} \mathrm{~V}^{2} \mathrm{~m}^{-2} \mathrm{~Hz}^{-1}$. Also seen are a number of plasma injections, some with enhanced chorus and $\mathrm{ECH}$ emissions.

[30] Preliminary results of the influence of terrestrial $\mathrm{Z}$ mode on electron acceleration have recently been reported [Xiao et al., 2012]. Z mode emission at Saturn is observed associated with narrowband emission as discussed by $Y e$ et al. [2010]. The clearest examples are the $5 \mathrm{kHz}$ narrowband emission as shown in Figure 9, but $\mathrm{Z}$ mode is also associated with upper hybrid emission near strong density gradients and source regions of $20 \mathrm{kHz}$ narrowband emission as discussed by Menietti et al. [2009, 2010]. In Figure 9 narrowband emission near $5 \mathrm{kHz}$ is seen both above and below $f_{c}$. Below $f_{c}$ the emission is composed of both $\mathrm{Z}$ and $\mathrm{O}$ mode emission as discussed by Ye et al. [2010]. Above $\mathrm{f}_{\mathrm{c}}$ only weaker $\mathrm{O}$ mode can propagate. The dominant $\mathrm{Z}$ mode intensities exceed $10^{-11} \mathrm{~V}^{2} \mathrm{~m}^{-2} \mathrm{~Hz}^{-1}$, and are often more intense. $5 \mathrm{kHz}$ narrowband is seen at all latitudes whereas $20 \mathrm{kHz}$ narrowband emission are only observed at relatively high latitudes [cf. Ye et al., 2009; Wang et al., 2010]. Ye et al. [2009] report that the $5 \mathrm{kHz} \mathrm{NB}$ emission originates from the northern and southern edges of the Enceladus plasma cloud in the range $8<\mathrm{L}<10$. However, it is now believed that $5 \mathrm{kHz} \mathrm{NB}$ emission also has a high-latitude, auroral source region [Ye et al., 2010]. 


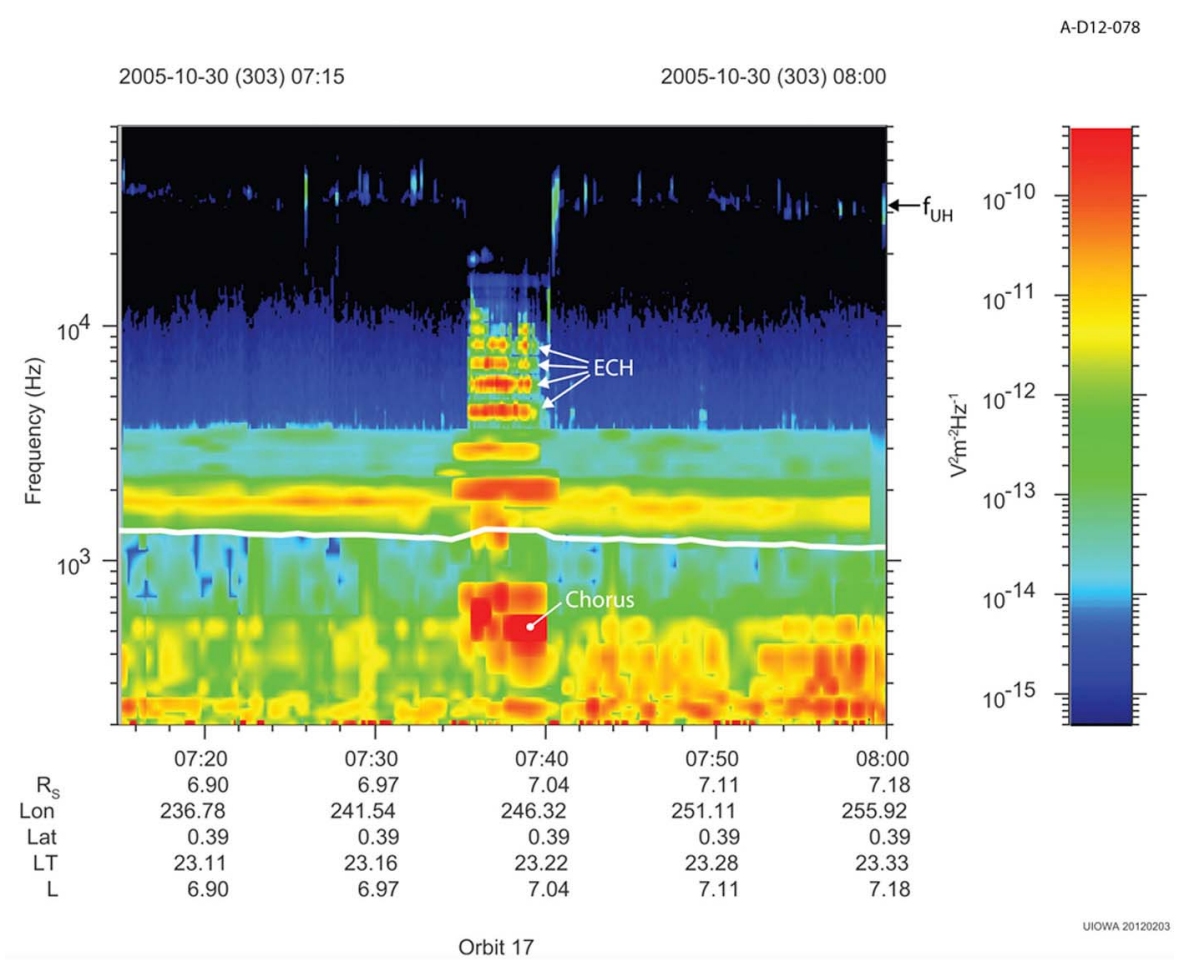

Figure 10. A plasma injection region observed by Cassini on day 303 of 2005. The upper hybrid frequency decreases within the event, indicating a lower density, and there is an enhancement of both chorus and ECH emission within the plasma injection region. The white line indicates $f_{c}$.

\subsection{Plasma Injection Regions}

[31] Hill [1976] and Hill et al. [1981] have discussed the role of plasma interchange or injection regions in the outer planets. In a rapidly rotating planet with an inner plasma source such as Jupiter and Saturn the inward transport of hot, tenuous plasma and outward transport of dense, cold plasma can be observed. Interchange events or plasma injection regions have been identified at Jupiter [cf. Bolton et al., 1997; Xiao et al., 2003] and at Saturn [cf. Hill et al., 2005; Burch et al., 2005; Menietti et al., 2008a; Rymer et al., 2008]. An example of a plasma injection region observed at Saturn is shown in Figure 10. It is seen that the upper hybrid frequency decreases within the event, indicating a lower density, and there is an enhancement of both chorus and ECH emission for this particular event. Chen and Hill [2008] have conducted a survey of the occurrence of such events at Saturn and found them to be present in the range 5 $<\mathrm{L}<10$ from 5 to $10 \%$ of the time. Since these regions have lower ratios of $f_{p} / f_{c}$, there could be an enhanced efficiency of momentum transport via diffusion. Tao et al. [2011] have investigated this as well as realistic wave normal angle distributions within plasma injection regions at Jupiter. They found that if the density ratio from inside to outside the injection region was at least $25 \%$, these regions could be effective at increasing the loss rate of $1-3 \mathrm{MeV}$ electrons. However, Tao et al. [2011] have not included the effect of the enhancement of the chorus emissions. Hence the effectiveness of injection events in the study of electron interactions with chorus remains an interesting question at both Jupiter and Saturn.

\section{Summary and Conclusions}

[32] In this paper we have compared chorus emissions observed at Jupiter and Saturn, and relate them to recent work of electron acceleration at Earth. Intense chorus emissions are observed near the magnetic equator, the likely source region, at each planet. The Galileo spacecraft orbited near the jovigraphic equator almost all the time, and the tilt of the magnetic field allowed a small range of magnetic latitudes to be sampled, $-13^{\circ}<\lambda<13^{\circ}$. Intensities of Jovian chorus emission do not appear to drop off with latitude, but the upper frequency cutoff of the emission does decrease. This is shown in Menietti et al. [2008b, Figure 8], where the upper limit of chorus is near $0.6 \mathrm{f}_{\mathrm{c}}$ near the magnetic equator but within $5^{\circ}$ falls to near $0.2 \mathrm{f}_{\mathrm{c}}$ in the northern hemisphere and $\sim 0.3 \mathrm{f}_{\mathrm{c}}$ in the southern hemisphere. High-inclination orbits at Saturn by Cassini reveal strong chorus intensities at latitudes extending to over $30^{\circ}$. Similar trends in upper frequency cutoff decreasing with latitude at Saturn are seen in Figure 7. The chorus upper cutoff frequency occurs $\sim 2.5^{\circ}$ away from the magnetic equator at $\sim 0.4 \mathrm{f}_{\mathrm{c}}$ and falls to $<0.1 \mathrm{f}_{\mathrm{c}}$ at $\sim 13^{\circ}$ magnetic latitude. The decrease in frequency with latitude appears to be nearly logarithmic in Figure 7 (top) and can be approximated by $\log _{10}(\mathrm{f}(\mathrm{Hz}))=$ $-0.0665 \lambda+3.41$ ( $\lambda$ is magnetic latitude in degrees). 
Table 1. Wave Observations Comparison

\begin{tabular}{lcccc}
\hline & Chorus $\left(\mathrm{nT}^{2}\right)$ & $\mathrm{f}_{\mathrm{L}}\left(\mathrm{f}_{\mathrm{c}}\right)$ & $\mathrm{f}_{\mathrm{u}}\left(\mathrm{f}_{\mathrm{c}}\right)$ & $\mathrm{ECH}\left(\mathrm{V}^{2} \mathrm{~m}^{-2}\right)$ \\
\hline Earth & $10^{-2}-10^{-1}$ & $<.1$ & $\sim 0.8$ & $10^{-6}$ \\
Jupiter & $10^{-2}$ & $<.1$ & $\sim 0.6$ & $2 \times 10^{-7}$ \\
Saturn & $10^{-3}$ & $<.1$ & $\sim 0.6$ & $10^{-7}$ \\
\hline
\end{tabular}

[33] At Jupiter the chorus emission is present at all local times and within the range of radial distances, $\sim 6 \mathrm{R}_{\mathrm{J}}<\mathrm{r}<$ $\sim 13 \mathrm{R}_{\mathrm{J}}$. The emission extends to highest frequency near the magnetic equator, but drops in intensity at the equator, where the density is highest within the plasma sheet. The minimum of chorus power near the magnetic equator is seen in the Jupiter data plotted at higher resolution and in the summary plot (Figure 7) of Menietti et al. [2008b]. Spectral densities are typically in the range $10^{-8}$ to $10^{-5} \mathrm{nT}^{2} \mathrm{~Hz}^{-1}$ and frequency ranges from a few hundred $\mathrm{Hz}$ to $5-8 \mathrm{kHz}$ are not uncommon. The effectiveness of electron acceleration via diffusion is strongly dependent on the ratio $f_{p} / f_{c}$, and this ratio decreases rapidly beyond about $7-8 R_{J}$, where chorus emission often is near peak intensity. In Figures 1-3 we observe ratios, $\mathrm{f}_{\mathrm{p}} / \mathrm{f}_{\mathrm{c}}<5$ frequently. For this reason we expect the contribution of chorus emission to electron acceleration to be significant at Jupiter, as suggested by Horne et al. [2008].

[34] At Saturn, the chorus emission is also present at all local times, but more commonly in the range $19 \mathrm{~h}<\mathrm{LT}<6$ $h$ (via midnight), and is usually in the range $4.5 R_{s}<r<8 R_{s}$. The source region is near the magnetic equator but the highest spectral densities occur a few degrees either side of the equator. Spectral densities are often in the range $10^{-8}$ to $10^{-6} \mathrm{nT}^{2} \mathrm{~Hz}^{-1}$, but occasionally do reach $10^{-5} \mathrm{nT}^{2} \mathrm{~Hz}^{-1}$, and therefore are generally an order of magnitude lower than those typically observed at Jupiter. The band width of chorus at Saturn rarely exceeds $2 \mathrm{kHz}$, again significantly lower than is observed at Jupiter. A comparison of characteristic chorus magnetic power levels with those often seen at Earth and Jupiter is presented in Table 1 . The intensity values for the Earth are typical of magnetic normal to active periods, while those for Jupiter and Saturn are typical examples, but are not the result of a comprehensive survey, which remains to be done. Table headings $f_{u}$ and $f_{L}$ indicate the upper and lower frequency limits for chorus emission.

[35] While at Jupiter initial studies reveal the chorus intensities are sufficient to accelerate electrons by a stochastic process [cf. Horne et al., 2008], the high-density levels near the source region of chorus at Saturn indicate a much less efficient process as suggested by Mauk and Fox [2010] and recently by Shprits et al. [2012]. At Saturn, the inner magnetosphere is dominated by Enceladus water ions from about $4 \mathrm{R}_{\mathrm{S}}$ to $\sim 6 \mathrm{R}_{\mathrm{S}}$, where $\mathrm{f}_{\mathrm{p}} / \mathrm{f}_{\mathrm{c}}>10$ near the magnetic equator. However, as seen in Figure 6 this ratio can decrease drastically at latitudes $>10^{\circ}$ where chorus is observed with significant intensity. This fact will be important in the details of electron-chorus interactions, as discussed in Shprits et al. [2012]. Plasma injection regions are also regions where $f_{p} / f_{c}$ can be much less than the surrounding magnetosphere and often chorus emissions have enhanced intensity within these regions. Since these regions have been observed at Saturn at all local times within $5<\mathrm{L}<10$ where chorus is observed, it will be important to study these regions as sources of local electron acceleration and/or scattering [cf. Tao et al., 2011]. Recently Tang and Summers [2012] have performed a comprehensive study of energetic electron fluxes at Saturn and found that at intermediate L shells, $5<\mathrm{L}<7$ (where chorus is observed) measured fluxes are close to the Kennel-Petschek limit. This is a good indication of whistler mode wave generation that limits trapped electron fluxes. In addition, the influence of chorus on electron acceleration and electron scattering at latitudes greater than $10^{\circ}$ needs to be studied at both Jupiter and Saturn.

[36] ECH emission is ubiquitous near the magnetic equator in the middle magnetosphere of both Jupiter and Saturn. These emissions are known to be sources of electron scattering into the loss cone but not as significant as chorus [cf. Horne and Thorne, 2000; Thorne et al., 2010]. Z mode emissions are observed at Jupiter associated with upper hybrid emission and narrow band kilometric emission (nKOM). At Saturn $\mathrm{Z}$ mode is observed also associated with upper hybrid emission and sources of narrowband emission. Recently, $\mathrm{Z}$ mode has been shown to be a potential source of electron acceleration at Earth [Xiao et al., 2012], and should be a subject of future study at both Jupiter and Saturn. Table 1 lists ECH electric power levels often observed at Earth, Jupiter, and Saturn. Z mode levels are more difficult to compare, because higher-frequency magnetic field strengths are not available at Saturn, and the emissions at Jupiter require more in-depth study to clearly distinguish $\mathrm{Z}$ mode from $\mathrm{O}$ mode, for instance.

[37] Acknowledgments. We wish to thank J. Barnholdt for administrative assistance and J. Chrisinger for help with several plots. J.D.M. acknowledges support from JPL contract 1415150 and NASA grant NNX11AM36G. Y.Y.S. wishes to cite support from NASA grants NNX09AF51G and NNX10AK99G. R.B.H. and E.E.W. were supported by STFC grant ST/I001727/1 and NERC.

[38] Masaki Fujimoto thanks the reviewers for their assistance in evaluating this paper.

\section{References}

Albert, J. M. (2002), Nonlinear interaction of outer zone electrons with VLF waves, Geophys. Res. Lett., 29(8), 1275, doi:10.1029/2001GL013941.

Albert, J. M. (2005), Evaluation of quasi-linear diffusion coefficients for whistler mode waves in a plasma with arbitrary density ratio, J. Geophys. Res., 110, A03218, doi:10.1029/2004JA010844.

Anderson, R. R., and K. Maeda (1977), VLF emissions associated with enhanced magnetospheric electrons, J. Geophys. Res., 82(1), 135-146, doi:10.1029/JA082i001p00135.

Bagenal, F. (1994), Empirical model of the Io plasma torus: Voyager measurements, J. Geophys. Res., 99(A6), 11,043-11,062, doi:10.1029/ 93JA02908.

Bell, T. F. (1984), The nonlinear gyroresonance interaction between energetic electrons and coherent VLF waves propagating at an arbitrary angle with respect to the Earth's magnetic field, J. Geophys. Res., 89(A2), 905918, doi:10.1029/JA089iA02p00905.

Benson, R. F., P. A. Webb, J. L. Green, D. L. Carpenter, V. S. Sonwalkar, H. G. James, and B. W. Reinisch (2006), Active wave experiments in space plasmas: The $\mathrm{Z}$ Mode, in Geospace Electromagnetic Waves and Radiation, edited by J. W. LaBelle and R. A. Treumann, pp. 3-35, Springer, Berlin, doi:10.1007/3-540-33203-0 1.

Berge, G. L., and S. Gulkis (1976), Earth-based radio observations of Jupiter: Millimeter to meter wavelengths, in Jupiter, edited by T. Gehrels, pp. 621-692, Univ. of Ariz. Press, Tucson.

Bolton, S. J., R. M. Thorne, D. A. Gurnett, W. S. Kurth, and D. J. Williams (1997), Enhanced whistler-mode emissions: Signatures of interchange motion in the Io torus, Geophys. Res. Lett., 24(17), 2123-2126, doi:10.1029/97GL02020.

Bolton, S. J., et al. (2002), Ultra-relativistic electrons in Jupiter's radiation belts, Nature, 415, 987-991, doi:10.1038/415987a. 
Bortnik, J., R. M. Thorne, and N. P. Meredith (2008), The unexpected origin of plasmaspheric hiss from discrete chorus emissions, Nature, 452(7183), 62-66, doi:10.1038/nature06741.

Bortnik, J., W. Li, R. M. Thorne, V. Angelopoulos, C. Cully, J. Bonnell, O. Le Contel, and A. Roux (2009), An observations linking the origin of plasmaspheric hiss to discrete chorus emissions, Science, 324, 775-778, doi: $10.1126 /$ science. 1171273 .

Brice, N., and T. R. McDonough (1973), Jupiter's radiation belts, Icarus, 18(2), 206-219, doi:10.1016/0019-1035(73)90204-2.

Burch, J. L., J. Goldstein, T. W. Hill, D. T. Young, F. J. Crary, A. J. Coates, N. André, W. S. Kurth, and E. C. Sittler Jr. (2005), Properties of local plasma injections in Saturn's magnetosphere, Geophys. Res. Lett., 32, L14S02, doi:10.1029/2005GL022611.

Carr, T. D., M. D. Desch, and J. K. Alexander (1983), Phenomenology of magnetospheric radio emissions, in Physics of the Jovian Magnetosphere, edited by A. J. Dessler, pp. 226-284, Cambridge Univ. Press, New York, doi:10.1017/CBO9780511564574.009.

Chen, Y., and T. W. Hill (2008), Statistical analysis of injection/dispersion events in Saturn's inner magnetosphere, J. Geophys. Res., 113, A07215, doi:10.1029/2008JA013166.

Church, S. R., and R. M. Thorne (1983), On the origin of plasmaspheric hiss: Ray path integrated amplification, J. Geophys. Res., 88, 7941-7957, doi:10.1029/JA088iA10p07941.

Divine, N., and H. B. Garrett (1983), Charged particle distributions in Jupiter's magnetosphere, J. Geophys. Res., 88(A9), 6889-6903, doi:10.1029/JA088iA09p06889.

Glauert, S. A., and R. B. Horne (2005), Calculation of pitch angle and energy diffusion coefficients with the PADIE code, J. Geophys. Res. 110, A04206, doi:10.1029/2004JA010851.

Gurnett, D. A., and A. Bhattacharjee (2005), Introduction to Plasma Physics, 379 pp., Cambridge Univ. Press, Cambridge, U. K.

Gurnett, D. A., and F. L. Scarf (1983), Plasma waves in the Jovian magnetosphere, in Physics of the Jovian Magnetosphere, edited by A. J. Dessler, pp. 285-316, Cambridge Univ. Press, Cambridge, U. K., doi:10.1017/ CBO9780511564574.010.

Gurnett, D. A., W. S. Kurth, and F. L. Scarf (1981), Plasma waves near Saturn: Initial results from Voyager 1, Science, 212(4491), 235-239, doi:10.1126/science.212.4491.235.

Gurnett, D. A., et al. (2005), Radio and plasma wave observations at Saturn form Cassini's approach and first orbit, Science, 307(5713), 1255-1259, doi:10.1126/science. 1105356 .

Hill, T. W. (1976), Interchange stability of a rapidly rotating magnetosphere, Planet. Space Sci., 24(12), 1151-1154, doi:10.1016/0032-0633 (76)90152-5.

Hill, T. W., A. J. Dessler, and L. J. Maher (1981), Corotating magnetospheric convection, J. Geophys. Res., 86(A11), 9020-9028, doi:10.1029/ JA086iA11p09020.

Hill, T. W., A. J. Dessler, and C. K. Goertz (1983), Magnetospheric models, in Physics of the Jovian Magnetosphere, edited by A. J. Dessler, pp. 353-394, Cambridge Univ. Press, New York, doi:10.1017/ CBO9780511564574.012.

Hill, T. W., A. M. Rymer, J. L. Burch, F. J. Crary, D. T. Young, M. F. Thomsen, D. Delapp, N. Andre, A. J. Coates, and G. R. Lewis (2005), Evidence for rotationally driven plasma transport in Saturn's magnetosphere, Geophys. Res. Lett., 32, L14S10, doi:10.1029/2005GL022620.

Horne, R. B., and R. M. Thorne (1998), Potential waves for relativistic electron scattering and stochastic acceleration during magnetic storms, Geophys. Res. Lett., 25(15), 3011-3014, doi:10.1029/98GL01002.

Horne, R. B., and R. M. Thorne (2000), Electron pitch angle diffusion by electrostatic electron cyclotron harmonic waves: The origin of pancake distributions, J. Geophys. Res., 105(A3), 5391-5402, doi:10.1029/ 1999JA900447.

Horne, R. B., and R. M. Thorne (2003), Relativistic electron acceleration and precipitation during resonant interactions with whistler-mode chorus, Geophys. Res. Lett., 30(10), 1527, doi:10.1029/2003GL016973.

Horne, R. B., R. M. Thorne, N. P. Meredith, and R. R. Anderson (2003a), Diffuse auroral electron scattering by electron cyclotron harmonic and whistler mode waves during an isolated substorm, J. Geophys. Res., 108(A7), 1290, doi:10.1029/2002JA009736.

Horne, R. B., S. A. Glauert, and R. M. Thorne (2003b), Resonant diffusion of radiation belt electrons by whistler-mode chorus, Geophys. Res. Lett., 30(9), 1493, doi:10.1029/2003GL016963.

Horne, R. B., et al. (2005a), Wave acceleration of electrons in the Van Allen radiation belts, Nature, 437, 227-230, doi:10.1038/nature03939.

Horne, R. B., R. M. Thorne, S. A. Glauert, J. M. Albert, N. P. Meredith, and R. R. Anderson (2005b), Timescale for radiation belt electron acceleration by whistler mode chorus waves, J. Geophys. Res., 110, A03225, doi:10.1029/2004JA010811.
Horne, R. B., R. M. Thorne, S. A. Glauert, J. D. Menietti, Y. Y. Shprits, and D. A. Gurnett (2008), Gyro-resonant electron acceleration at Jupiter, Nat Phys., 4, 301-304, doi:10.1038/nphys897.

Hospodarsky, G. B., T. F. Averkamp, W. S. Kurth, D. A. Gurnett, J. D. Menietti, O. Santolík, and M. K. Dougherty (2008), Observations of chorus at Saturn using the Cassini radio and plasma science wave instrument, J. Geophys. Res., 113, A12206, doi:10.1029/2008JA013237.

Hospodarsky, G. B., K. Sigsbee, J. S. Leisner, J. D. Menietti, W. S. Kurth, D. A. Gurnett, C. Kletzing, and O. Santolík (2011), Plasma wave observations at Earth, Jupiter, and Saturn, paper presented at Chapman Conference on Dynamics of the Earth's Radiation Belts and Inner Magnetosphere, AGU, St. John's, Newfoundland and Labrador, Canada, 17-22 July.

Katoh, Y., and Y. Omura (2007a), Computer simulation of chorus wave generation in the Earth's inner magnetosphere, Geophys. Res. Lett., 34 , L03102, doi:10.1029/2006GL028594.

Katoh, Y., and Y. Omura (2007b), Relativistic particle acceleration in the process of whistler-mode chorus wave generation, Geophys. Res. Lett., 34, L13102, doi:10.1029/2007GL029758.

Katoh, Y., F. Tsuchiya, Y. Miyoshi, A. Morioka, H. Misawa, R. Ujiie, W. S. Kurth, A. T. Tomas, and N. Krupp (2011), Whistler mode chorus enhancements in association with energetic electron signatures in the Jovian magnetosphere, J. Geophys. Res., 116, A02215, doi:10.1029/ 2010JA016183.

Kennel, C. F., and H. E. Petschek (1966), Limit on stably trapped particle fluxes, J. Geophys. Res., 71, 1-28, doi:10.1029/JZ071i001p00001.

Kidder, A., R. M. Winglee, and E. M. Harnett (2009), Regulation of the centrifugal interchange cycle in Saturn's inner magnetosphere, J. Geophys. Res., 114, A02205, doi:10.1029/2008JA013100.

Kurth, W. S., D. D. Barbosa, D. A. Gurnett, and F. L. Scarf (1980), Electrostatic waves in the Jovian magnetosphere, Geophys. Res. Lett., 7(1), 57-60, doi:10.1029/GL007i001p00057.

LeDocq, M. J., D. A. Gurnett, and G. B. Hospodarsky (1998), Chorus source locations from VLF Poynting flux measurements with the Polar spacecraft, Geophys. Res. Lett., 25(21), 4063-4066, doi:10.1029/ 1998GL900071.

Li, W., R. M. Thorne, V. Angelopoulis, J. Bortnik, C. M. Cully, B. Ni, O Le Contel, A. Roux, U. Auster, and W. Magnes (2009), Global distribution of whistler-mode chor $u s$ waves observed on the THEMIS spacecraft, Geophys. Res. Lett., 36, L09104, doi:10.1029/2009GL037595.

Li, W., et al. (2010), THEMIS analysis of observed equatorial electron distributions responsible for the chorus excitation, J. Geophys. Res., 115, A00F11, doi:10.1029/2009JA014845.

Mauk, B. H., and N. J. Fox (2010), Electron radiation belts of the solar system, J. Geophys. Res., 115, A12220, doi:10.1029/2010JA015660.

Menietti, J. D. and P. H. Yoon (2006), Plasma waves and fine structure emission bands within a plasmapause density cavity source region, Geophys. Res. Lett., 33, L15101, doi:10.1029/2005GL025610.

Menietti, J. D., D. A. Gurnett, and J. B. Groene (2001), Narrow-band kilometric radio emission as observed by the Galileo plasma wave instrument, Planet. Space Sci., 49(3-4), 385-393, doi:10.1016/S0032-0633 (00)00159-8.

Menietti, J. D., O. Santolík, A. M. Rymer, G. B. Hospodarsky, A. M. Persoon, D. A. Gurnett, A. J. Coates, and D. T. Young (2008a), Analysis of plasma waves observed within local plasma injections seen in Saturn's magnetosphere, J. Geophys. Res., 113, A05213, doi:10.1029/ 2007JA012856.

Menietti, J. D., R. B. Horne, D. A. Gurnett, G. B. Hospodarsky, C. W. Piker, and J. B. Groene (2008b), A survey of Galileo plasma wave instrument observations of Jovian whistler-mode chorus, Ann. Geophys., 26 , 1819-1828, doi:10.5194/angeo-26-1819-2008.

Menietti, J. D., O. Santolík, A. M. Rymer, G. B. Hospodarsky, D. A. Gurnett, and A. J. Coates (2008c), Analysis of plasma waves observed in the inner Saturn magnetosphere, Ann. Geophys., 26, 2631-2644, doi:10.5194/angeo-26-2631-2008

Menietti, J. D., S.-Y. Ye, P. H. Yoon, O. Santolík, A. M. Rymer, D. A Gurnett, and A. J. Coates (2009), Analysis of narrowband emission observed in the Saturn magnetosphere, J. Geophys. Res., 114, A06206, doi:10.1029/2008JA013982.

Menietti, J. D., P. H. Yoon, S.-Y. Ye, B. Cecconi, and A. M. Rymer (2010), Source mechanism of Saturn narrowband emission, Ann. Geophys., 28 1013-1021, doi:10.5194/angeo-28-1013-2010.

Meredith, N. P., R. B. Horne, and R. R. Anderson (2001), Substorm dependence of chorus amplitudes: Implications for the acceleration of electrons to relativistic energies, J. Geophys. Res., 106(A7), 13,165-13,178, doi:10.1029/2000JA900156.

Meredith, N. P., R. B. Horne, R. H. A. Iles, R. M. Thorne, D. Heynderickx, and R. R. Anderson (2002), Outer zone relativistic electron acceleration 
associated with substorm-enhanced whistler mode chorus, J. Geophys. Res., 107(A7), 1144, doi:10.1029/2001JA900146.

Meredith, N. P., M. Cain, R. B. Horne, R. M. Thorne, D. Summers, and R. R. Anderson (2003), Evidence for chorus-driven electron acceleration to relativistic energies from a survey of geomagnetically disturbed periods, J. Geophys. Res., 108(A6), 1248, doi:10.1029/2002JA009764.

Meredith, N. P., R. B. Horne, R. M. Thorne, and R. R. Anderson (2009), Survey of upper band chorus and ECH waves: Implications of the diffuse aurora, J. Geophys. Res., 114, A07218, doi:10.1029/2009JA014230.

Nunn, D. (1974), A self-consistent theory of triggered VLF emissions, Planet. Space Sci., 22(3), 349-378, doi:10.1016/0032-0633(74)90070-1. Nunn, D., Y. Omura, H. Matsumoto, I. Nagano, and S. Yagitani (1997), The numerical simulation of VLF chorus and discrete emissions observed on the Geotail satellite using a Vlasov code, J. Geophys. Res., 102(A12), 27,083-27,097, doi:10.1029/97JA02518.

Omura, Y., and D. Summers (2006), Dynamics of high-energy electrons interacting with whistler mode chorus emissions in the magnetosphere, J. Geophys. Res., 111, A09222, doi:10.1029/2006JA011600.

Omura, Y., D. Nunn, H. Matsumoto, and M. J. Rycroft (1991), A review of observational, theoretical and numerical studies of VLF triggered emissions, J. Atmos. Terr. Phys., 53(5), 351-368, doi:10.1016/0021-9169 (91)90031-2.

Omura, Y., N. Furuya, and D. Summers (2007), Relativistic turning acceleration of resonant electrons by coherent whistler mode waves in a dipole magnetic field, J. Geophys. Res., 112, A06236, doi:10.1029/ 2006JA012243

Omura, Y., Y. Katoh, and D. Summers (2008), Theory and simulation of the generation of whistler-mode chorus, J. Geophys. Res., 113, A04223, doi:10.1029/2007JA012622

Omura, Y., M. Hikishima, Y. Katoh, D. Summers, and S. Yagitani (2009), Nonlinear mechanisms of lower-band and upper-band VLF chorus emissions in the magnetosphere, J. Geophys. Res., 114, A07217, doi:10.1029/ 2009JA014206.

Rymer, A. M., B. H. Mauk, T. W. Hill, C. Paranicas, D. G. Mitchell, A. J. Coates, and D. T. Young (2008), Electron circulation in Saturn's magnetosphere, J. Geophys. Res., 113, A01201, doi:10.1029/2007JA012589.

Santolík, O., and D. A. Gurnett (2003), Transverse dimensions of chorus in the source region, Geophys. Res. Lett., 30(2), 1031, doi:10.1029/ 2002GL016178

Santolík, O., D. A. Gurnett, J. S. Pickett, M. Parrot, and N. CornilleauWehrlin (2003), Spatio-temporal structure of storm-time chorus, J. Geophys. Res., 108(A7), 1278, doi:10.1029/2002JA009791.

Santolík, O., D. A. Gurnett, J. S. Pickett, M. Parrot, and N. CornilleauWehrlin (2004), A microscopic and nanoscopic view of storm-time chorus on 31 March 2001, Geophys. Res. Lett., 31, L02801, doi:10.1029/ 2003 GL018757.

Santolík, O., J. Chum, M. Parrot, D. A. Gurnett, J. S. Pickett, and N. Cornilleau-Wehrlin (2006), Propagation of Whistler-mode chorus to low altitudes: Spacecraft observations of structured ELF hiss, J. Geophys. Res., 111, A10208, doi:10.1029/2005JA011462.

Scarf, F. L., D. A. Gurnett, W. S. Kurth, and R. L. Poynter (1982), Voyager 2 plasma wave observations at Saturn, Science, 215(4532), 587-594, doi:10.1126/science.215.4532.587.

Schippers, P., et al. (2008), Multi-instrument analysis of electron populations in Saturn's magnetosphere, J. Geophys. Res., 113, A07208, doi:10.1029/2008JA013098

Schippers, P., N. Andre, D. A. Gurnett, G. R. Lewis, A. M. Persoon, and A. J. Coates (2012), Identification of electron field-aligned current systems in Saturn's magnetosphere, J. Geophys. Res., 117, A05204, doi:10.1029/2011JA017352.

Shprits, Y. Y., R. M. Thorne, R. B. Horne, S. A. Glauert, M. Cartwright, C. T. Russell, D. N. Baker, and S. G. Kanekal (2006a), Acceleration mechanism responsible for the formation of the new radiation belt during the 2003 Halloween solar storm, Geophys. Res. Lett., 33, L05104, doi:10.1029/2005GL024256.

Shprits, Y. Y., R. M. Thorne, R. B. Horne, and D. Summers (2006b), Bounce-averaged diffusion coefficients for field-aligned chorus waves, J. Geophys. Res., 111, A10225, doi:10.1029/2006JA011725.
Shprits, Y. Y., J. D. Menietti, X. Gu, K.-C. Kim, and R. B. Horne (2012), Gyro-resonant interactions between the radiation belt electrons and whistler mode chorus waves in the radiation environments of Earth, Jupiter, and Saturn, a comparative study, J. Geophys. Res., 117, A11216, doi:10.1029/2012JA018031.

Summers, D., and Y. Omura (2007), Ultra-relativistic acceleration of electrons in planetary magnetospheres, Geophys. Res. Lett., 34, L24205, doi:10.1029/2007GL032226.

Summers, D., R. M. Thorne, and F. Xiao (1998), Relativistic theory of wave-particle resonant diffusion with application to electron acceleration in the magnetosphere, J. Geophys. Res., 103(A9), 20,487-20,500, doi:10.1029/98JA01740.

Summers, D., C. Ma, N. P. Meredith, R. B. Horne, R. M. Thorne, D. Heynderickx, and R. R. Anderson (2002), Model of the energization of the outer zone electrons by whistler-mode chorus during the October 9, 1990, geomagnetic storm, Geophys. Res. Lett., 29(24), 2174, doi:10.1029/2002GL016039.

Summers, D., R. Tang, and Y. Omura (2011), Effects of nonlinear wave growth on extreme radiation belt electron fluxes, J. Geophys. Res., 116, A10226, doi:10.1029/2011JA016602.

Tang, R., and D. Summers (2012), Energetic electron fluxes at Saturn from Cassini observations, J. Geophys. Res., 117, A06221, doi:10.1029/ 2011JA017394.

Tao, X., R. M. Thorne, R. B. Horne, B. Ni, J. D. Menietti, Y. Y. Shprits, and D. A. Gurnett (2011), Importance of plasma injection events for energization of relativistic electrons in the Jovian magnetosphere, J. Geophys. Res., 116, A01206, doi:10.1029/2010JA016108.

Thorne, R. M. (1983), Microscopic plasma processes in the Jovian magnetosphere, in Physics of the Jovian Magnetosphere, edited by A. J. Dessler, pp. 454-488, Cambridge Univ. Press, Cambridge, U. K., doi:10.1017 CBO9780511564574.014.

Thorne, R. M., T. P. Armstrong, S. Stone, D. J. Williams, R. W. McEntire, S. J. Bolton, D. A. Gurnett, and M. G. Kivelson (1997), Galileo evidence for rapid interchange transport in the Io torus, Geophys. Res. Lett., 24(17), 2131-2134, doi:10.1029/97GL01788.

Thorne, R. M., T. P. O'Brien, Y. Y. Shprits, D. Summers, and R. B. Horne (2005), Timescale for $\mathrm{MeV}$ electron microburst loss during geomagnetic storms, J. Geophys. Res., 110, A09202, doi:10.1029/2004JA010882.

Thorne, R. M., B. Ni, X. Tao, R. B. Horne, and N. P. Meredith (2010), Scattering by chorus waves as the dominant cause of diffuse auroral precipitation, Nature, 467, 943-946, doi:10.1038/nature09467.

Tomás, A. T., J. Woch, N. Krupp, A. Lagg, K.-H. Glassmeier, and W. S. Kurth (2004), Energetic electrons in the inner part of the Jovian magnetosphere and their relation to auroral emissions, J. Geophys. Res., 109, A06203, doi:10.1029/2004JA010405.

Trakhtengerts, V. Y. (1999), A generation mechanism for chorus emission, Ann. Geophys., 17, 95-100, doi:10.1007/s00585-999-0095-4.

Tsurutani, B. T., and E. J. Smith (1974), Postmidnight chorus: A substorm phenomenon, J. Geophys. Res., 79(1), 118-127, doi:10.1029/ JA079i001p00118.

Wang, Z., D. A. Gurnett, G. Fischer, S.-Y. Ye, W. S. Kurth, D. G. Mitchell, J. S. Leisner, and C. T. Russell (2010), Cassini observations of narrowband radio emissions in Saturn's magnetosphere, J. Geophys. Res., 115, A06213, doi:10.1029/2009JA014847.

Xiao, F., R. M. Thorne, D. A. Gurnett, and D. J. Williams (2003), Whistler mode excitation and electron scattering during an interchange event near Io, Geophys. Res. Lett., 30(14), 1749, doi:10.1029/2003GL017123.

Xiao, F., S. Zhang, Z. Su, Z. He, and L. Tang (2012), Rapid acceleration of radiation belt energetic electrons by Z-mode waves, Geophys. Res. Lett., 39, L03103, doi:10.1029/2011GL050625.

Ye, S.-Y., D. A. Gurnett, G. Fischer, B. Cecconi, J. D. Menietti, W. S. Kurth, Z. Wang, G. B. Hospodarsky, P. Zarka, and A. Lecacheux (2009), Source locations of narrowband radio emissions detected at Saturn, J. Geophys. Res., 114, A06219, doi:10.1029/2008JA013855.

Ye, S.-Y., J. D. Menietti, G. Fischer, Z. Wang, B. Cecconi, D. A. Gurnett, and W. S. Kurth (2010), Z mode waves as the source of Saturn narrowband radio emissions, J. Geophys. Res., 115, A08228, doi:10.1029/ 2009JA015167. 